Non-Tumor 


\title{
C2K Non-Tumor
}

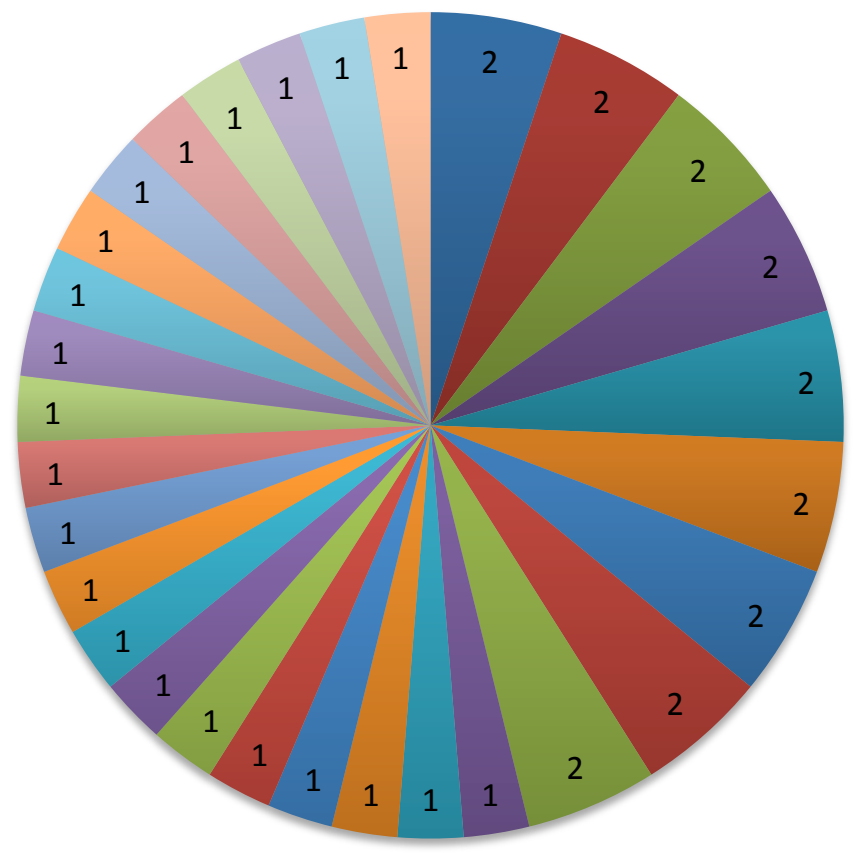

\author{
ENSGALG00000027175 \\ LINGO2 \\ GMDS \\ MED12 \\ - FAM19A2 \\ - TBC1D4 \\ ENSGALG00000013357 \\ ENSGALG00000016393
}




\section{C2Br Non-Tumor}

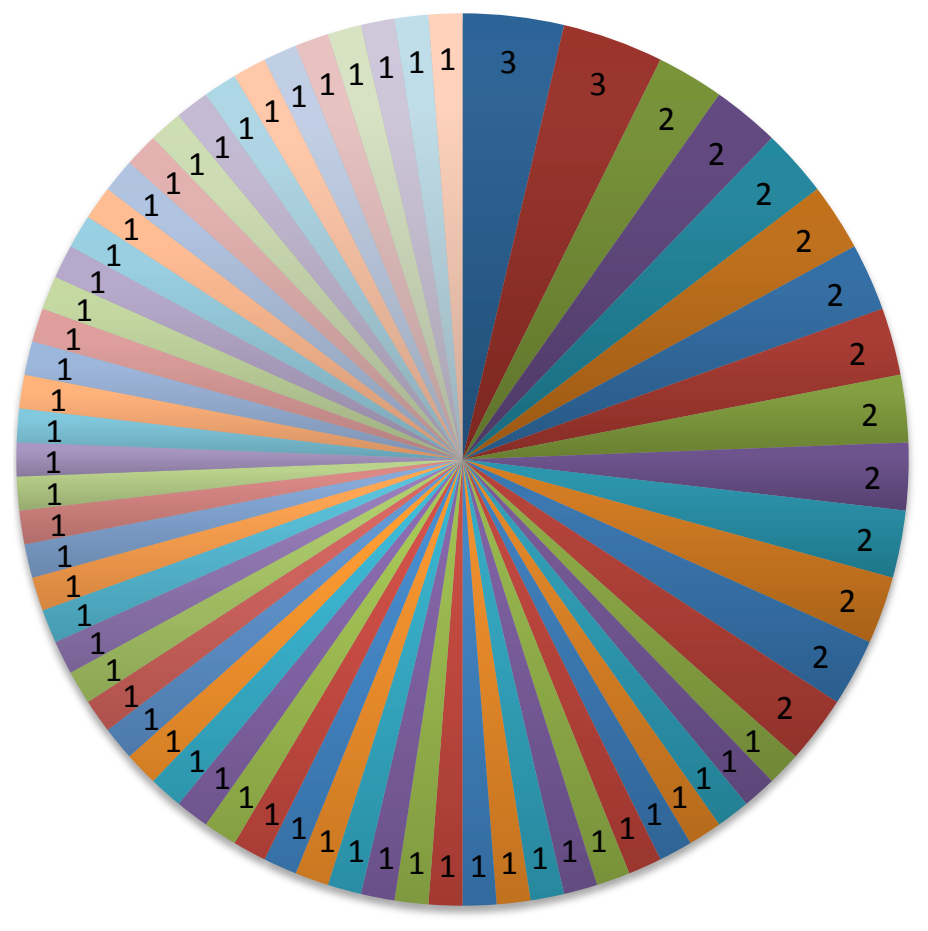

-TAB2

- LSM5

MCMDC2

- NADSYN1

- CCDC85C

ITPRIP

CLPX

GMNN

- protein_coding

- PSME4

FLVCR1

SH3BP2

- SP3

- ERBB2IP

GBE1 


\section{C4Br Non-Tumor}

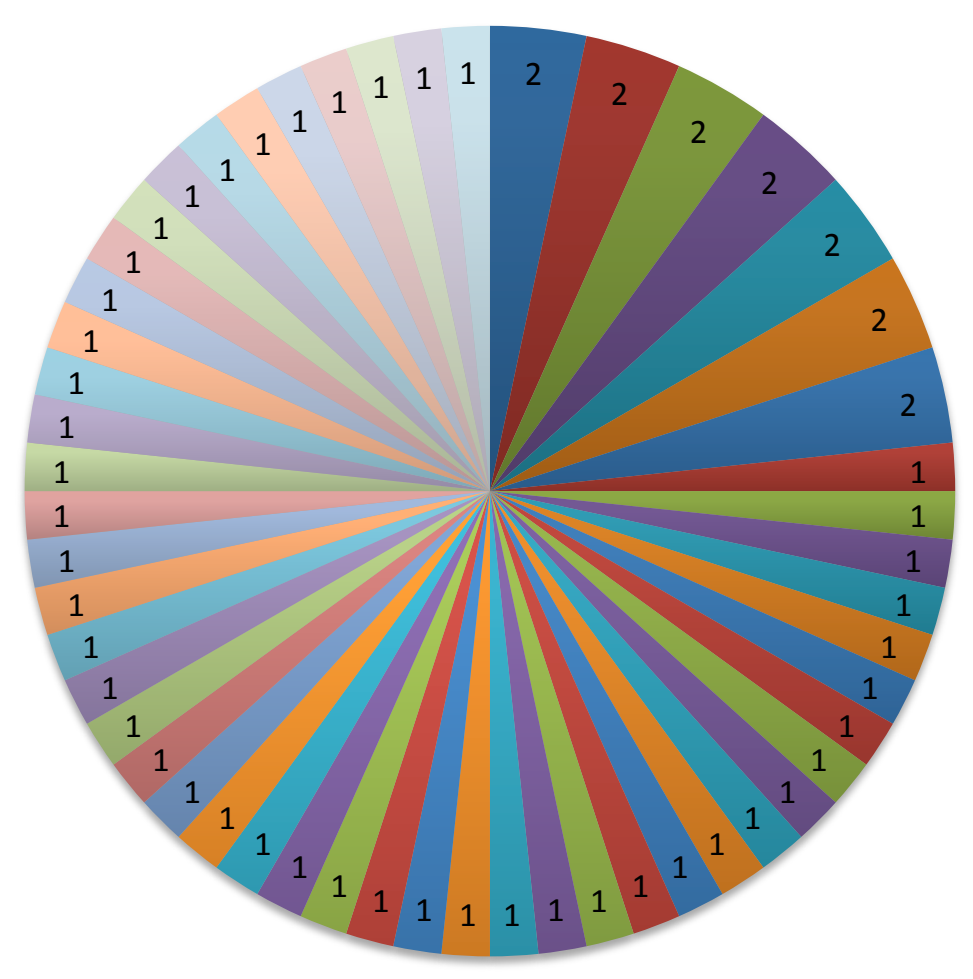

- F1NHT9_CHICK

- WDR20

protein_coding

DUNX1 - Q90813_CHICK

BEND6

protein_coding

a protein_coding

ALV sequence by blast (perfect match) protein_coding 


\section{D1K Non-Tumor}

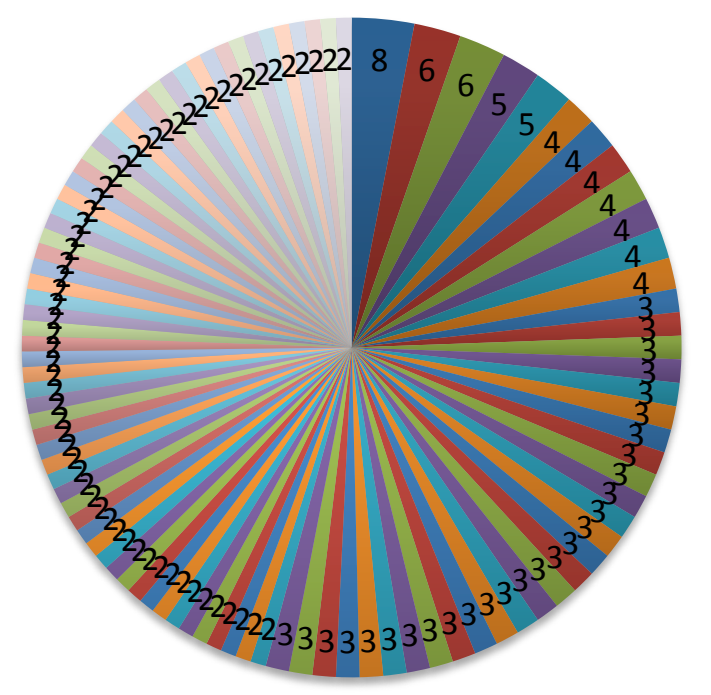

- TRIO

-ZNF518B

-TCF7L2

- NUTF2

DENSGALT00000022624

- CSNK1E

- NSD1

- PEMT

- IFT140 


\section{D3K Non-Tumor}

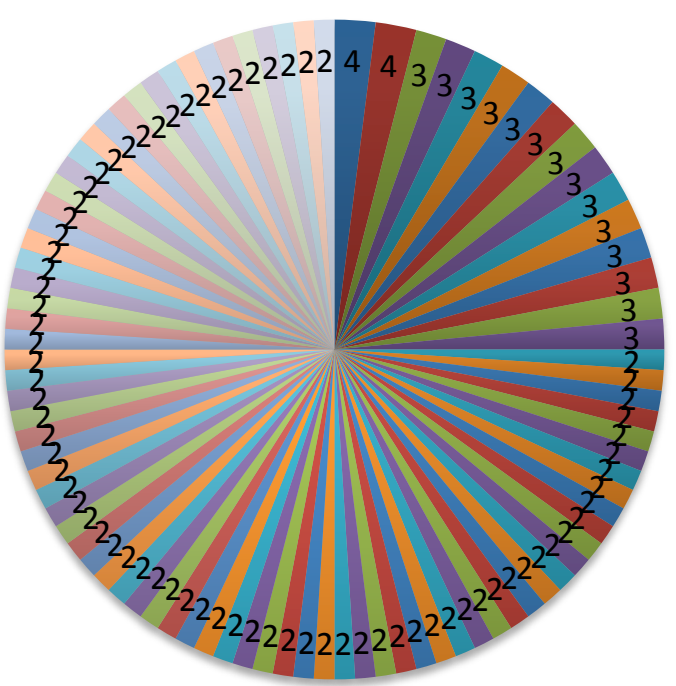

- HOXA2

- LMO4

E ENSGALT00000028943

n ENSGALT00000019288

" ENSGALT00000025873

- CTDSPL2

ENSGALG00000014171

ENSGALG00000027614

[ ENSGALT00000018638 


\section{Inflammation}




\section{B8L Inflammation}

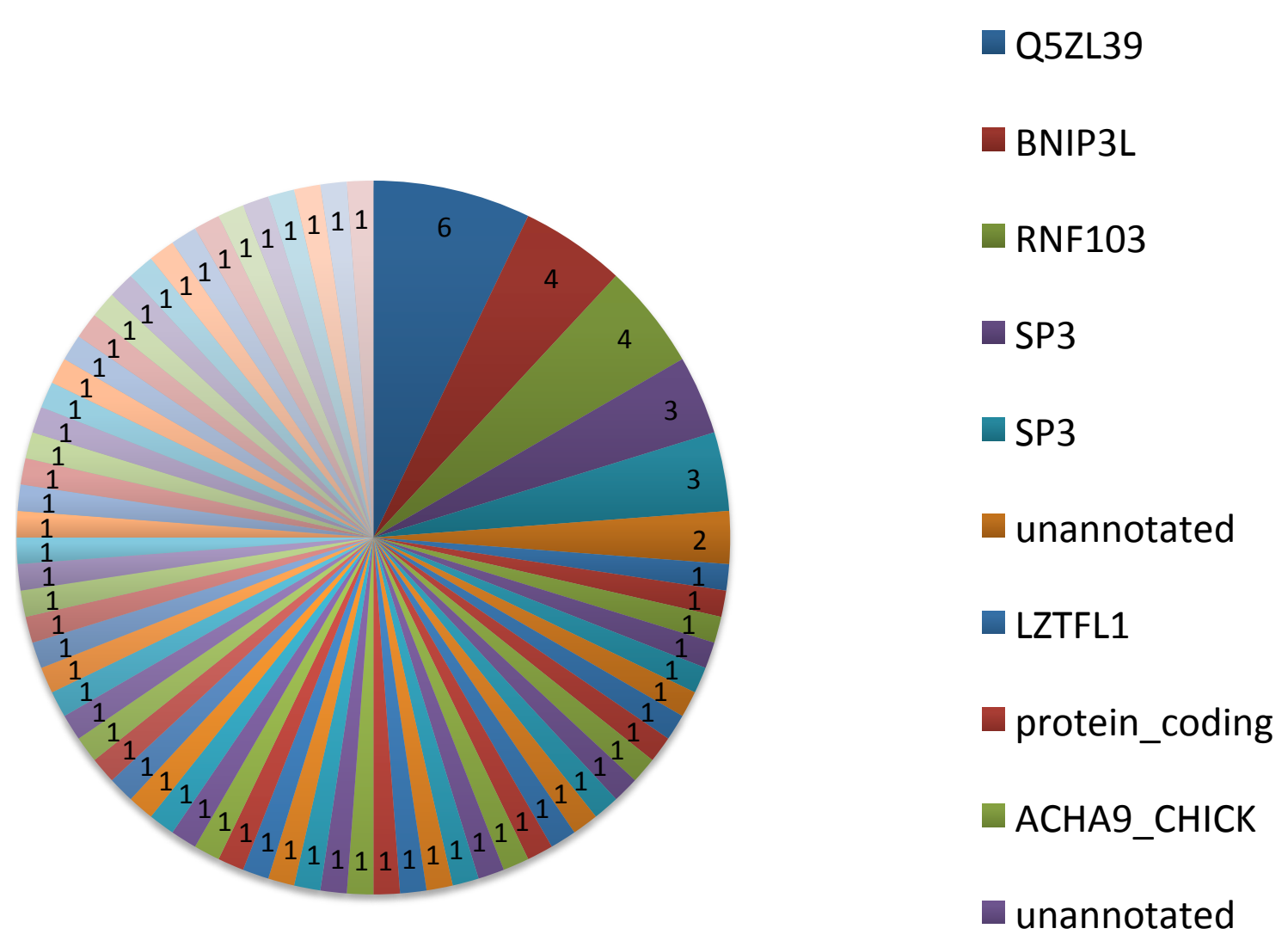




\section{D4L Inflammation}

aLS2CL

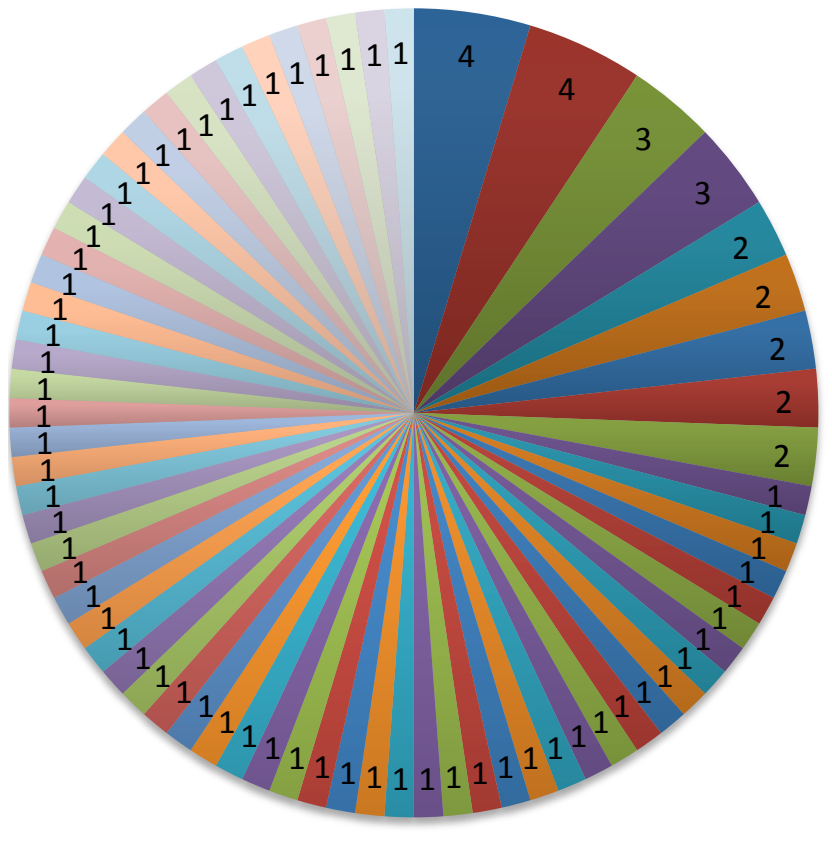

uprotein_coding

- Q6XFRO_CHICK

- KIAA1524

EPHA3

aNKRD42

- VEGFA_CHICK 
Neoplastic follicle 


\title{
A6B Neoplastic Follicle
}

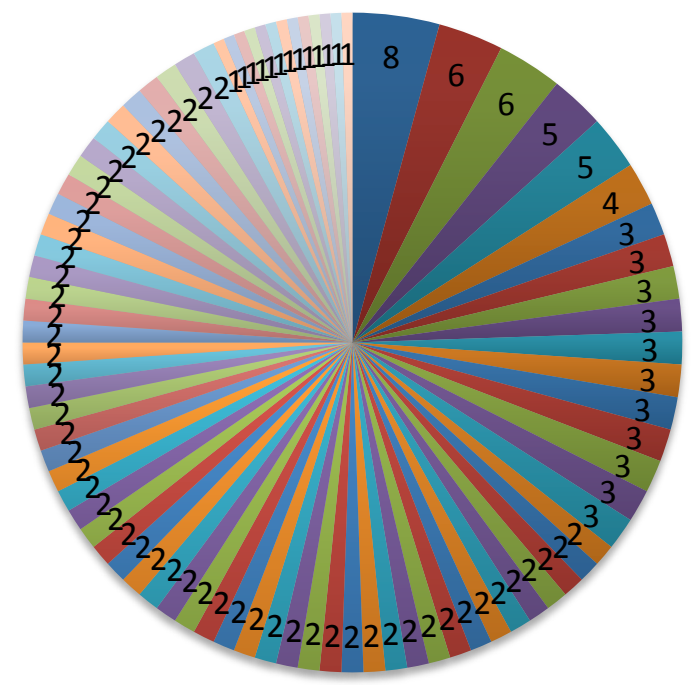

\author{
- CAPN9 \\ - TMEM251 \\ - HSPA8 \\ - CCNC \\ ELP3 \\ ambiguous \\ ¿YXX \\ -TNFRSF1A \\ - ENSGALG00000027489
}




\title{
A9B Neoplastic Follicle
}

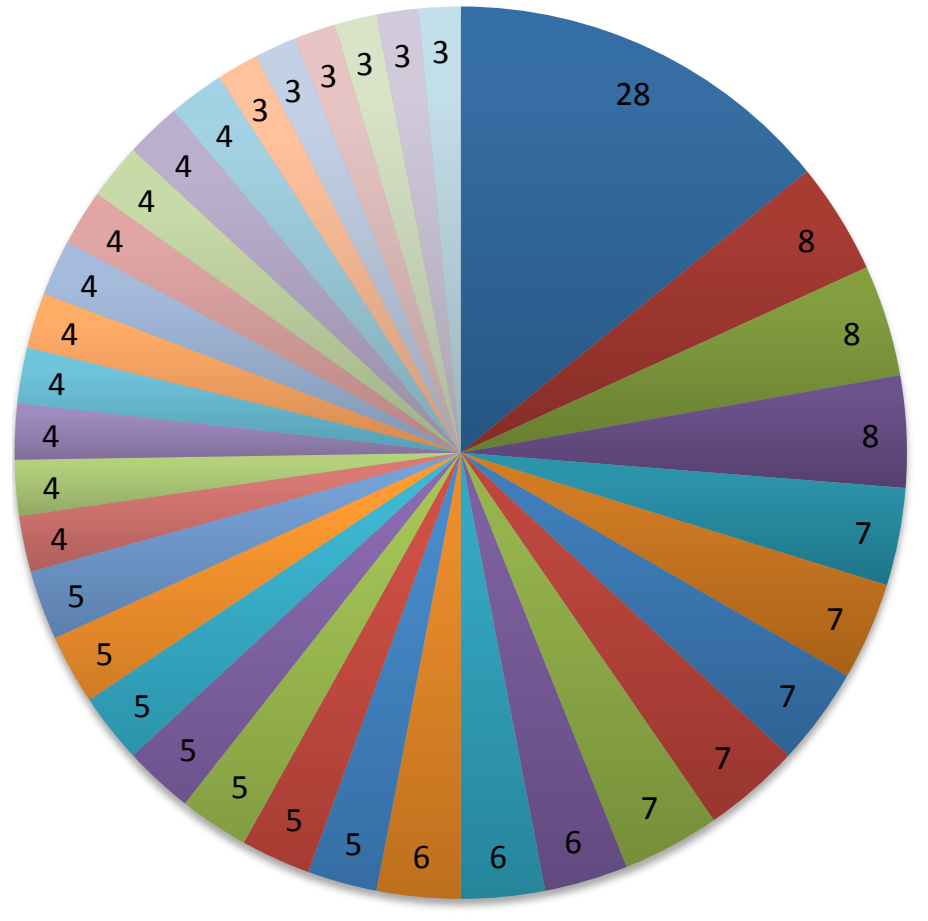

\author{
aTAD1 \\ - ABHD6 \\ DCUN1D3 \\ ENSGALG00000027143 \\ MKL1 \\ - ILDR2 \\ RBM26 \\ - CANT1 \\ SKIDA1 \\ TNFRSF1A \\ C15H12ORF49 \\ DUSP10 \\ VWA3A \\ - PRDM10 \\ FKBP1B \\ CCNA2 \\ - PCBP3
}




\title{
D1B Neoplastic Follicle
}

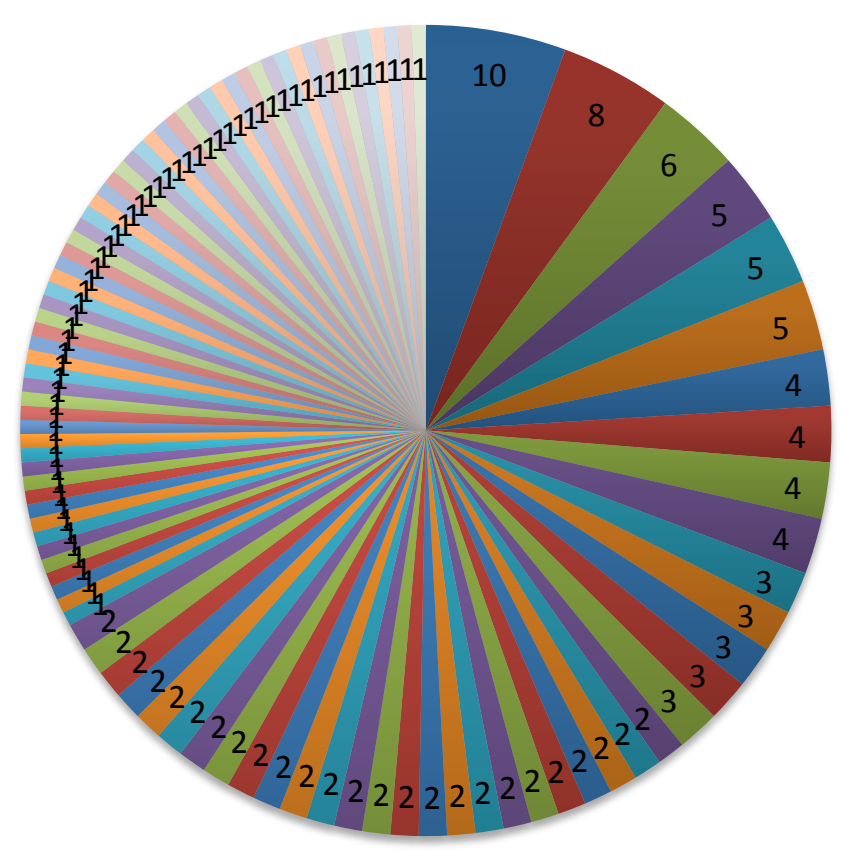

\author{
- FAM107B \\ Q Q5F455_CHICK \\ - FAM129A \\ - AKR1A1 \\ NRCAM \\ - CYTH3 \\ NUP85 \\ NCOA2 \\ KCNMA1 \\ NARG2 \\ - Q9PST8_CHICK \\ PHOSPHO1 \\ - PP2AA_CHICK \\ - SAMD8 \\ PARP9 \\ SLC37A3 \\ Q Q5ZLS9_CHICK \\ DSCAM
}




\section{D10B Neoplastic Follicle}

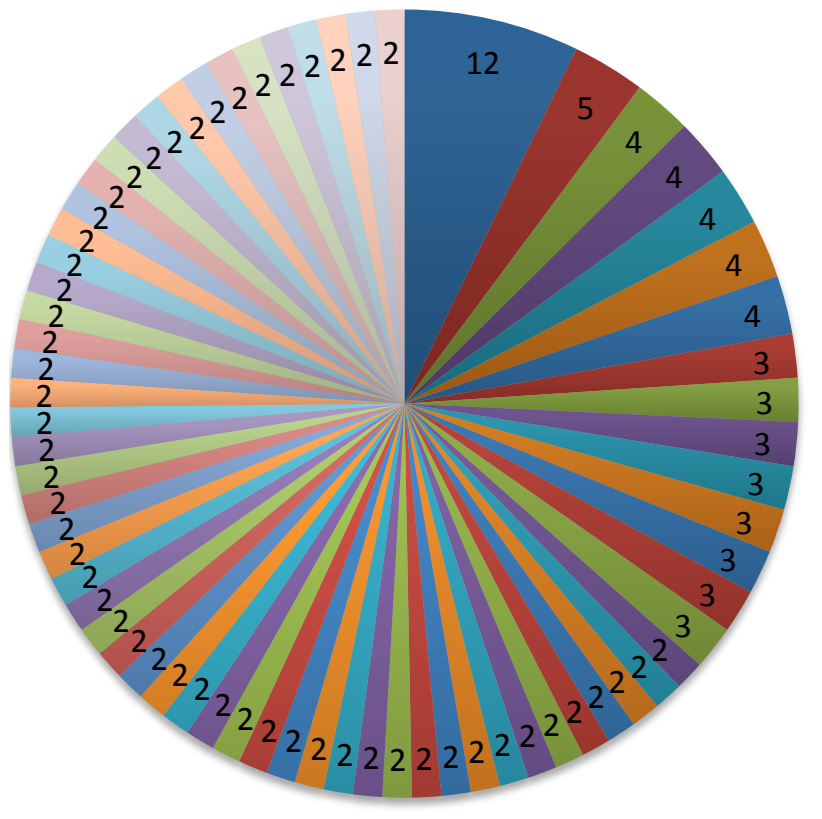

- KLHL5

- KDELC1

- STARD13

- PRKRIR

- TRPS1

HOXB13

FOXN3

U6

CRYL1

- HIVEP1

AZIN1

AJAP1

BCL11A

- PTDSS2

FAM134A 


\section{D6B Neoplastic Follicle}
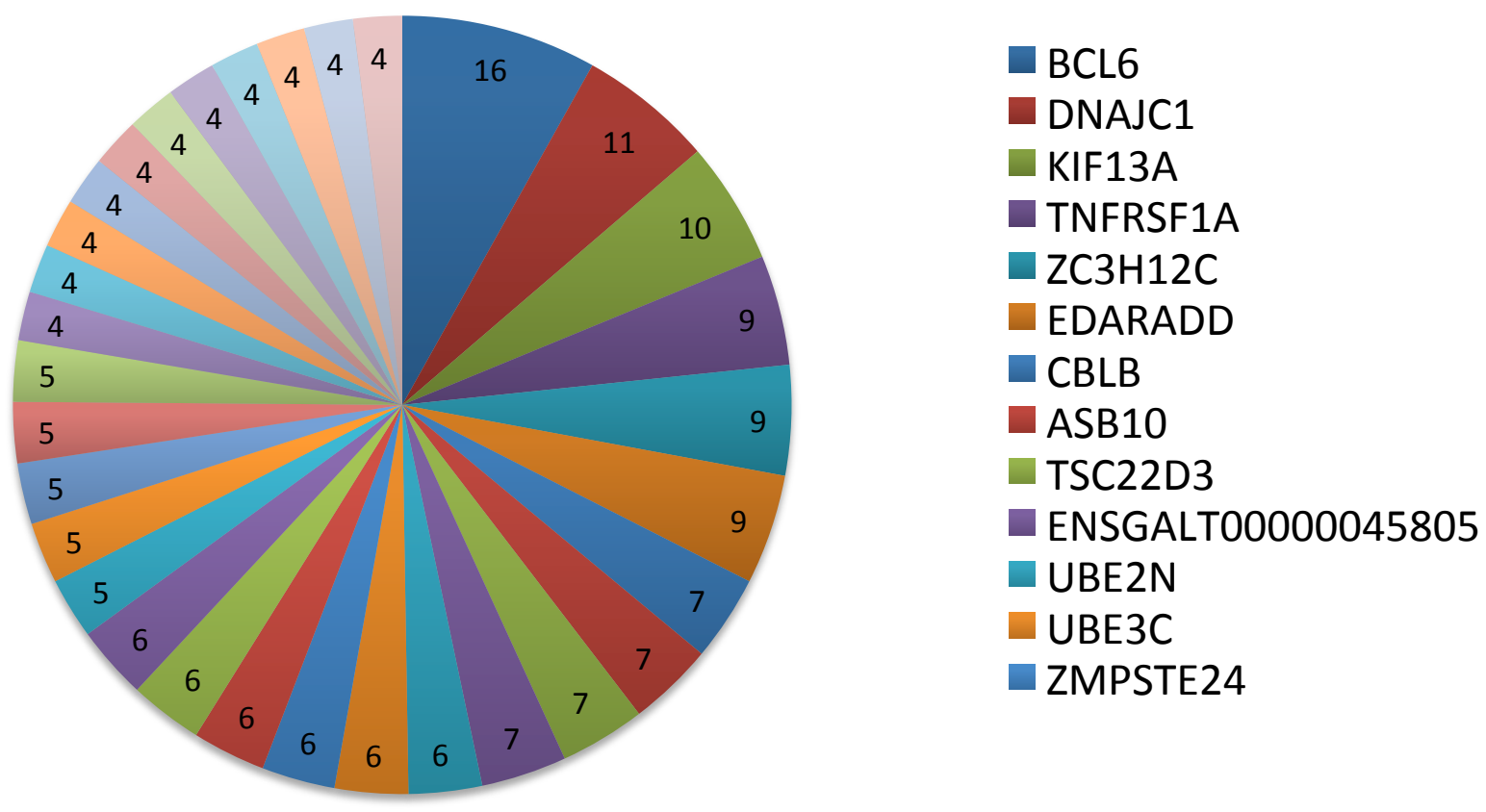
Bursa Tumors 


\section{A1B Tumor}

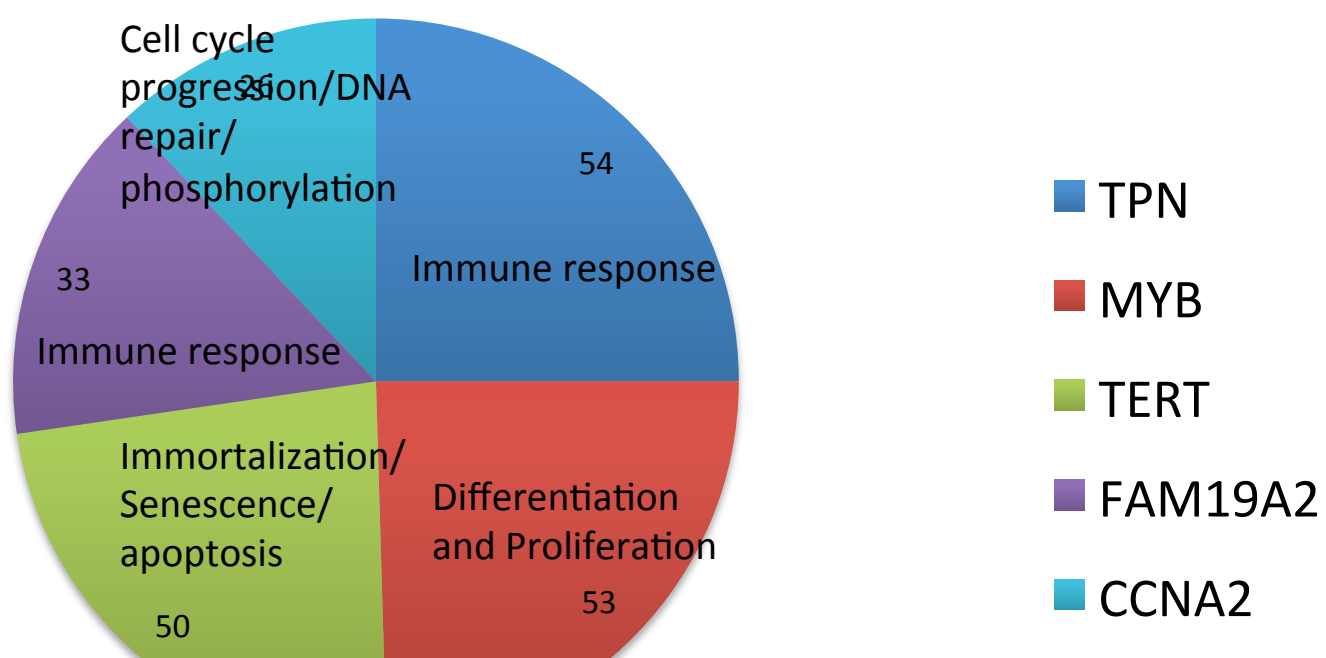




\section{A2B Tumor}

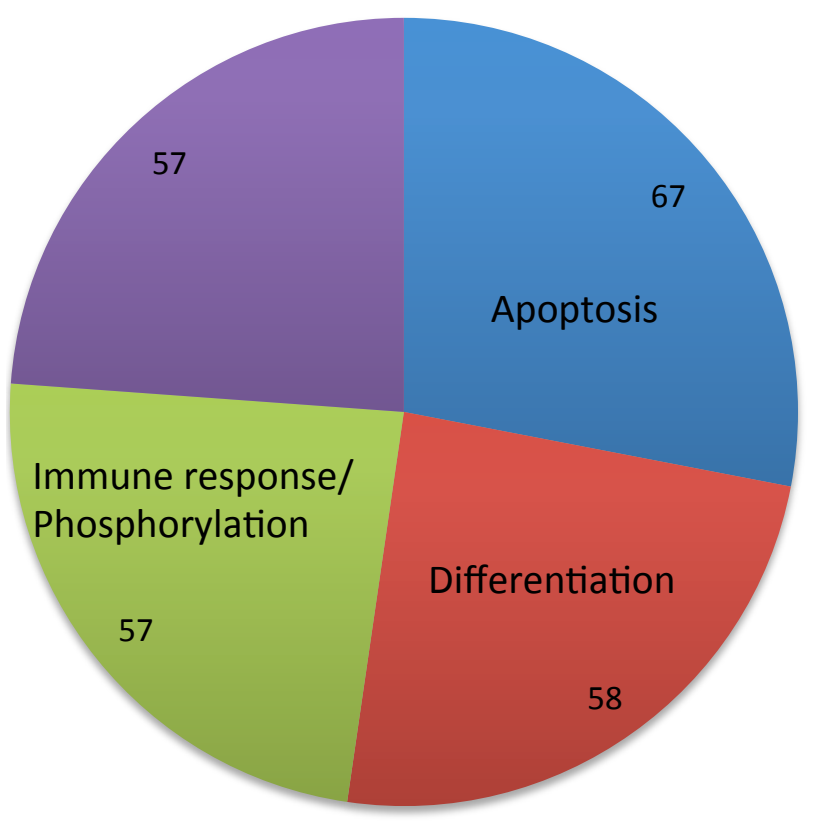

MAP1S

BTBD1

TAB2

ENSGALG00000020884 


\section{A4B Tumor}

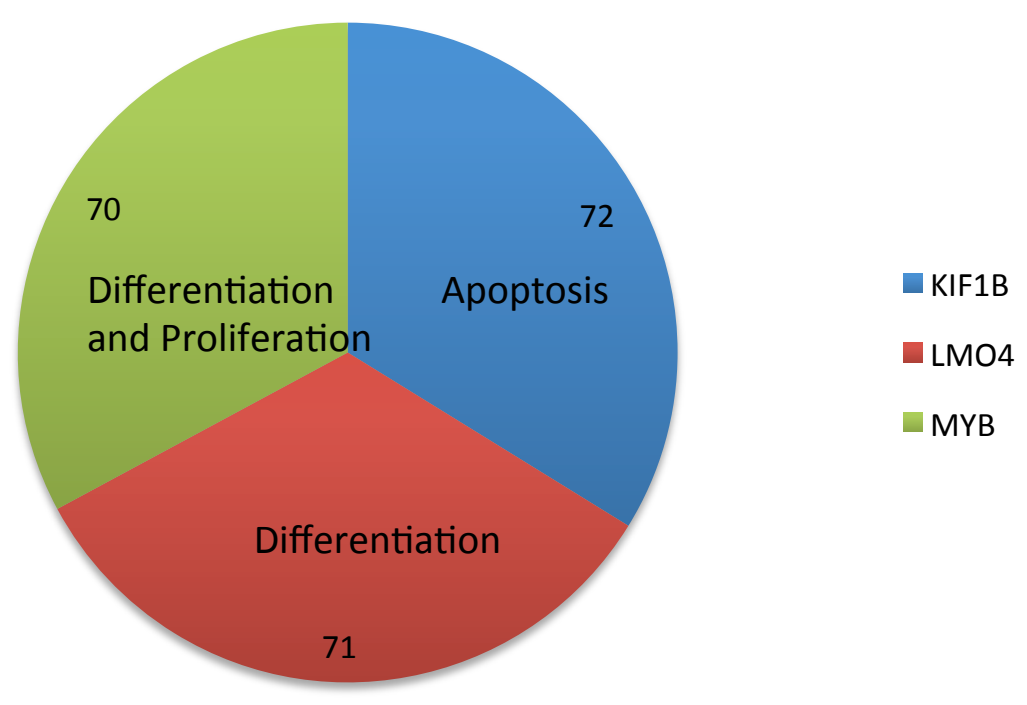




\section{A5B Tumor}

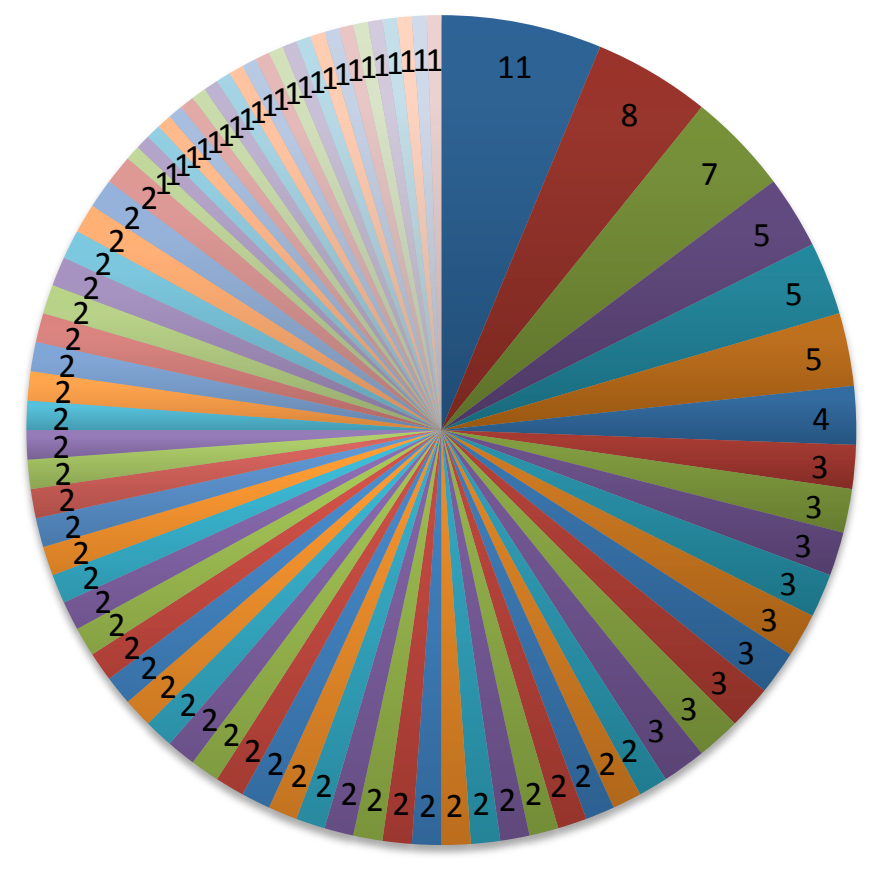

C-MYB

ENSGALG00000019412

C-MYB

- AMBRA1

UMPS

JAM2

ENSGALG00000005049

- HMGN2

KIAA1522

CREBBP 


\section{A8B Tumor}

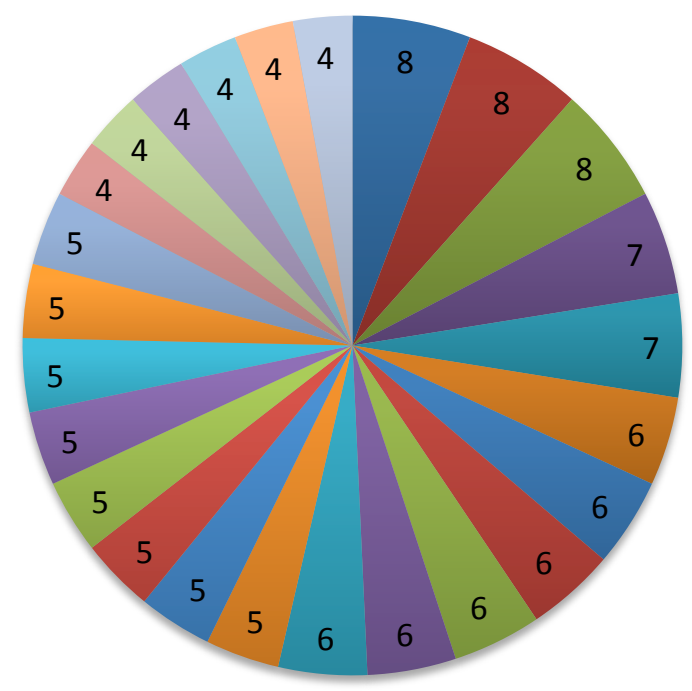

- VSTM2L

nBAS

ambiguous

- PXDN

RFWD2

PACSIN2

- ATP10A

- ENSGALT00000036508

- ARFGAP1 


\title{
B3B Tumor
}

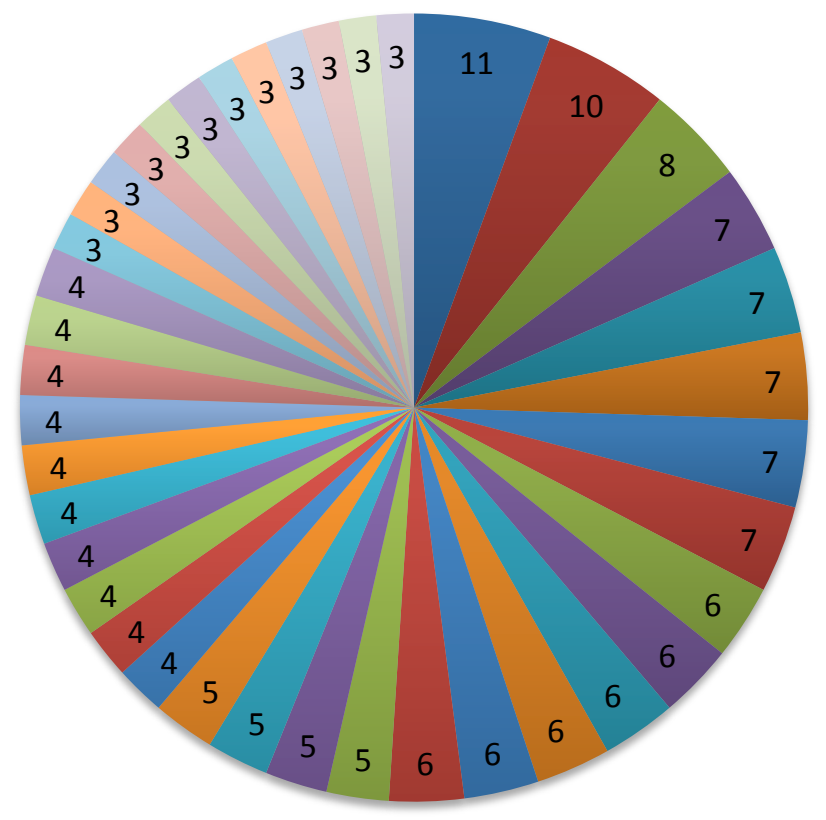

\author{
- PCM1 \\ - ZMIZ1 \\ ABCC4 \\ TNFRSF1A \\ RS1 \\ ENSGALG00000004169 \\ - TBC1D14 \\ - PCNX \\ ENSGALT00000044410 \\ RTN4R \\ CFUC-TIX
}




\section{B4B Tumor}

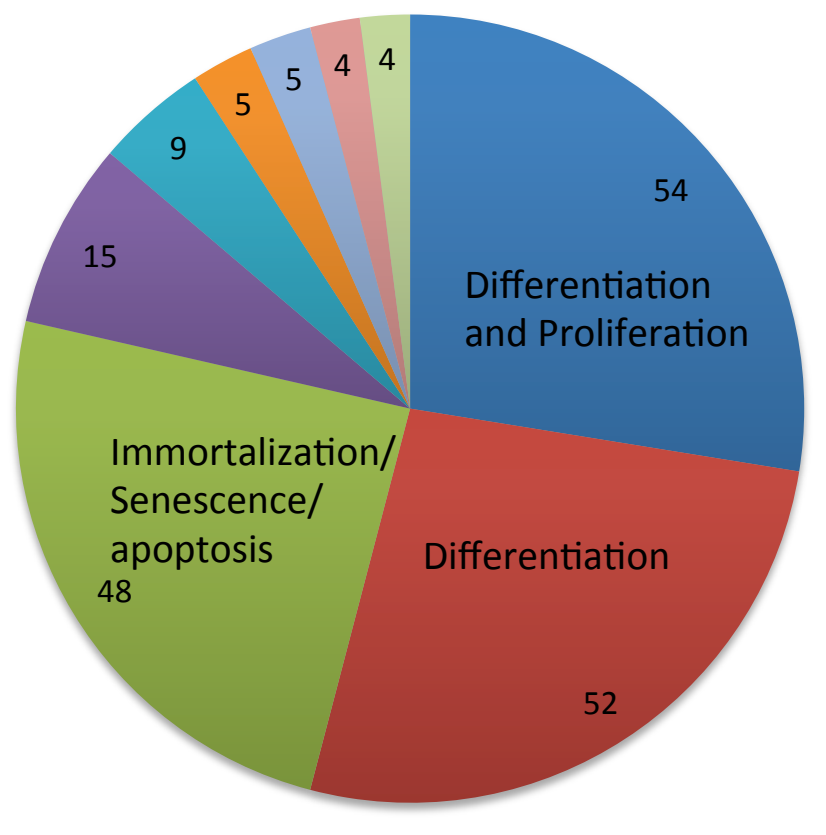

- MYB

a SEL1L

- TERT

- FAM19A2

- VOPP1

- TCF12

$\mathrm{ZC} 2 \mathrm{HC} 1 \mathrm{~B}$

-TMCC3

ENSGALT00000007451 


\section{B6B Tumor}

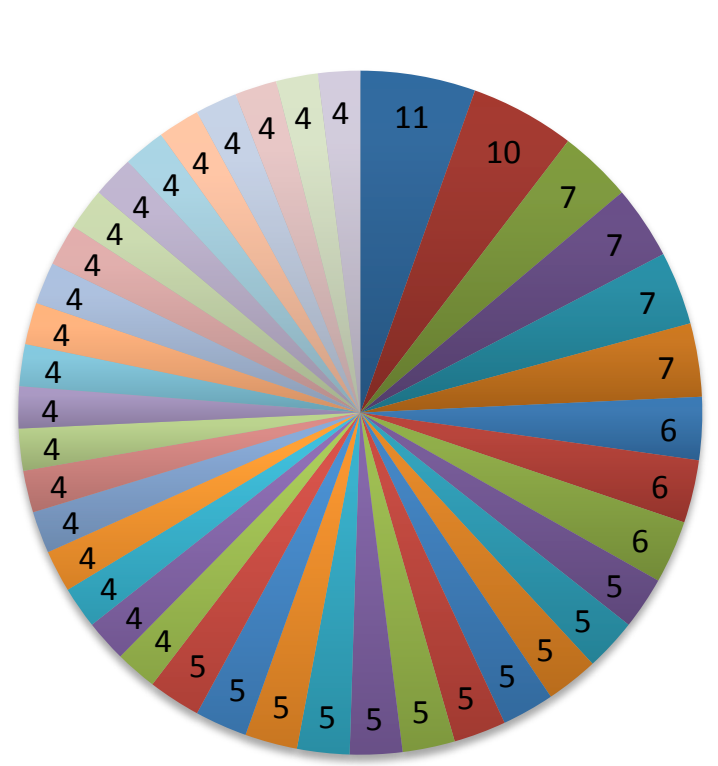

DAZL

KLRG2

gga-let-7d

- CCNY

- SERTAD2

CL2

TNFRSF1A

- RB1CC1

STOX2

TNFRSF1A

- TMEM135 


\section{B8B Tumor}

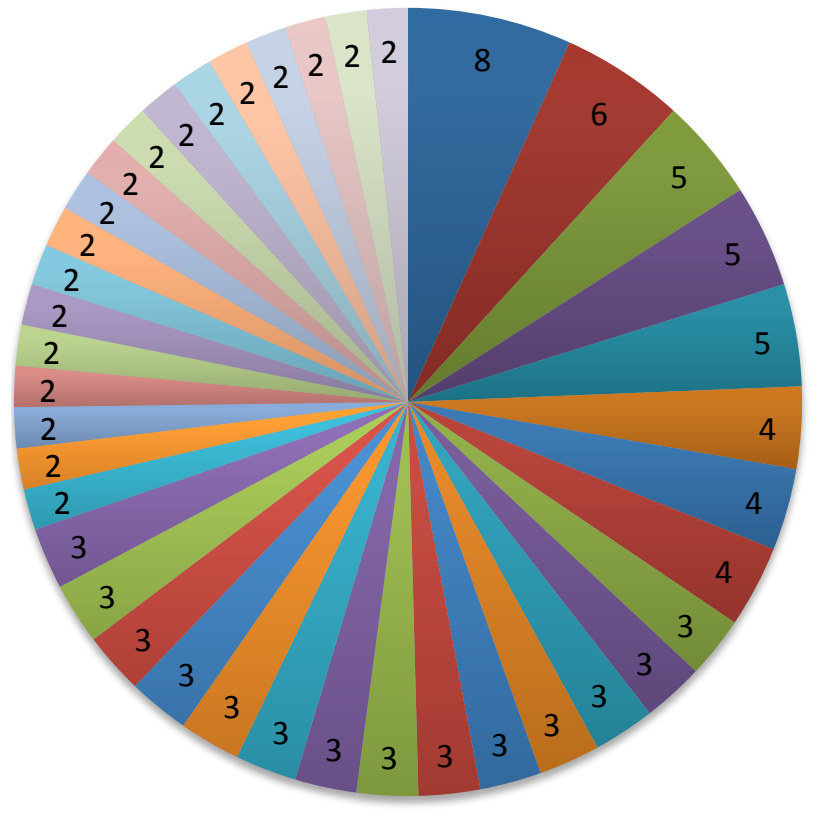

ambiguous

- CCNA2

ELL

ambiguous

ambiguous

ZDHHC17

KDM2B

ALDH8A1

ENSGALG00000007917

AMN1

ENSGALT00000025685

gga-mir-3533 


\title{
C2B Tumor
}

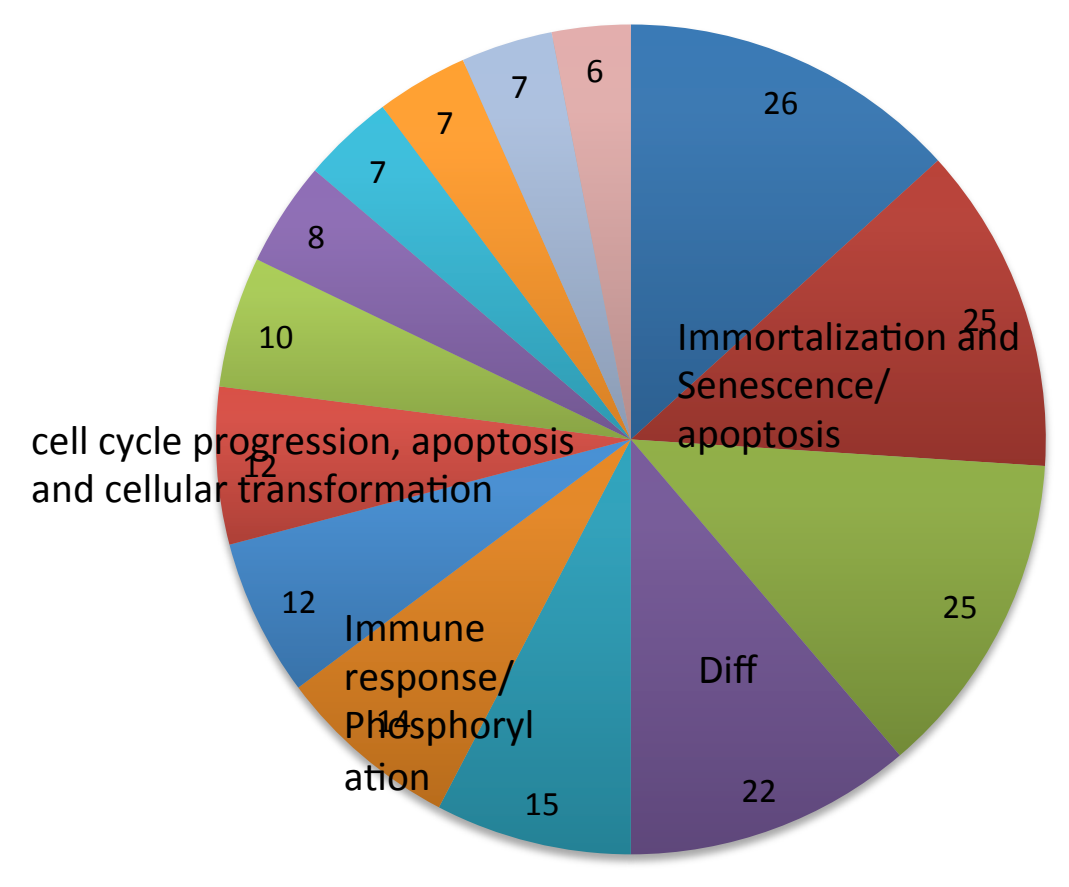

\author{
- TERT \\ - TERT \\ - TERT \\ - HTT \\ C5H11ORF58 \\ TAB2 \\ TERT \\ MYC \\ NFI1 \\ ESCO1 \\ TNFRSF1A \\ TERT \\ DCAKD \\ ENSGALG00000014722
}




\section{C5B Tumor}

NOX3

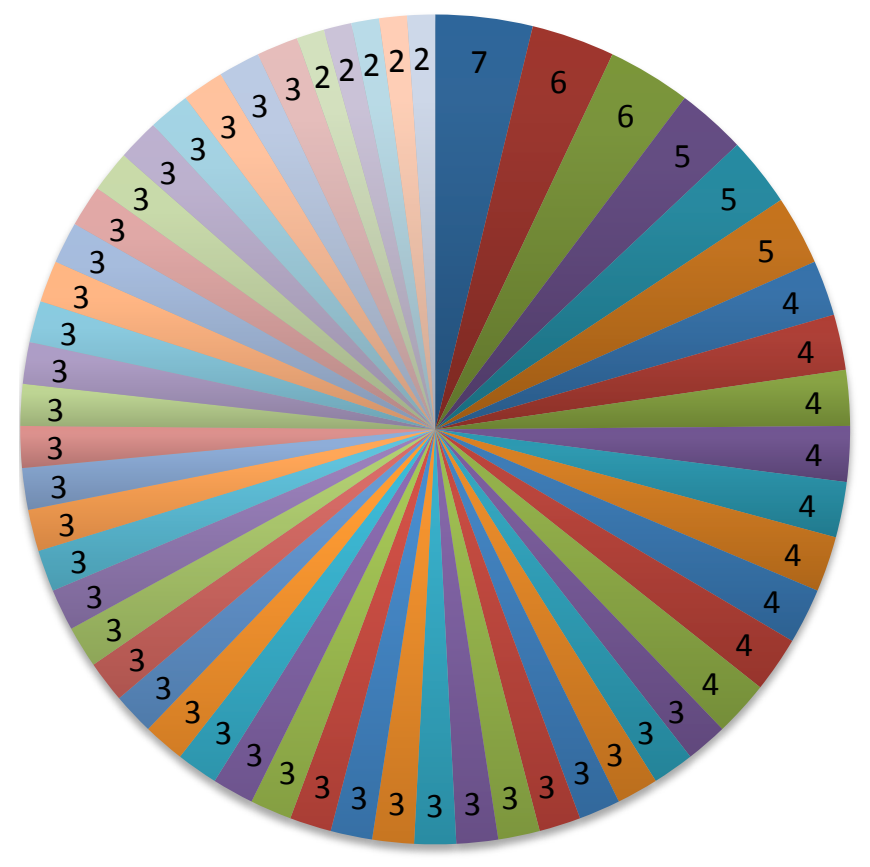

NFI1

TERT

ENSGALT00000020674

MYB

NUDT13

- LRRC58

CBLB

RBM26

- BRCA2

MED31

TGIF1 


\section{C6B Tumor}

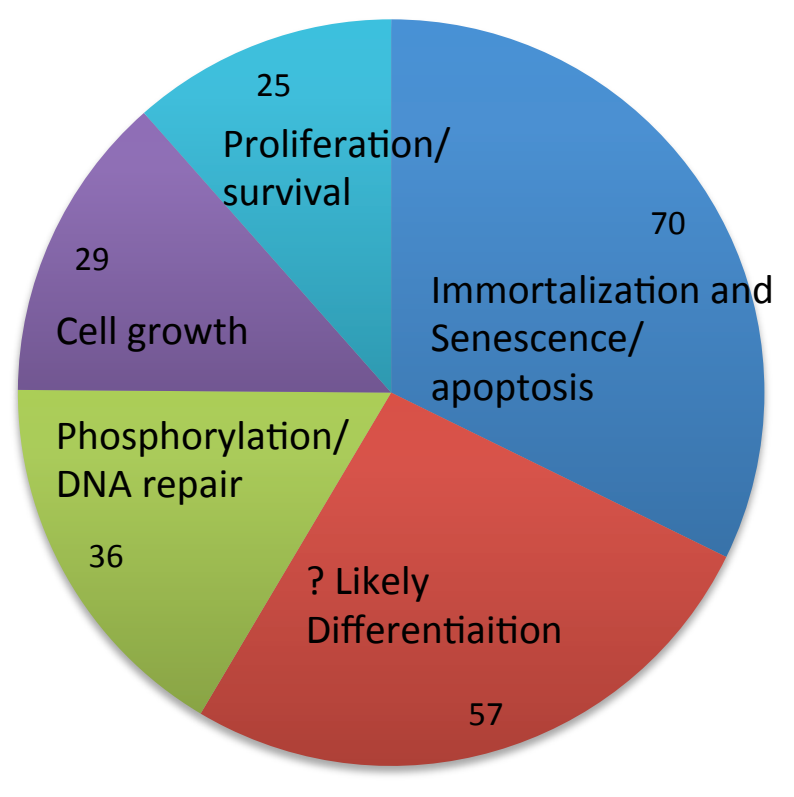

- TERT

ZNF518B

SMEK1

- SHOX

EGFR 


\section{C7B Tumor}

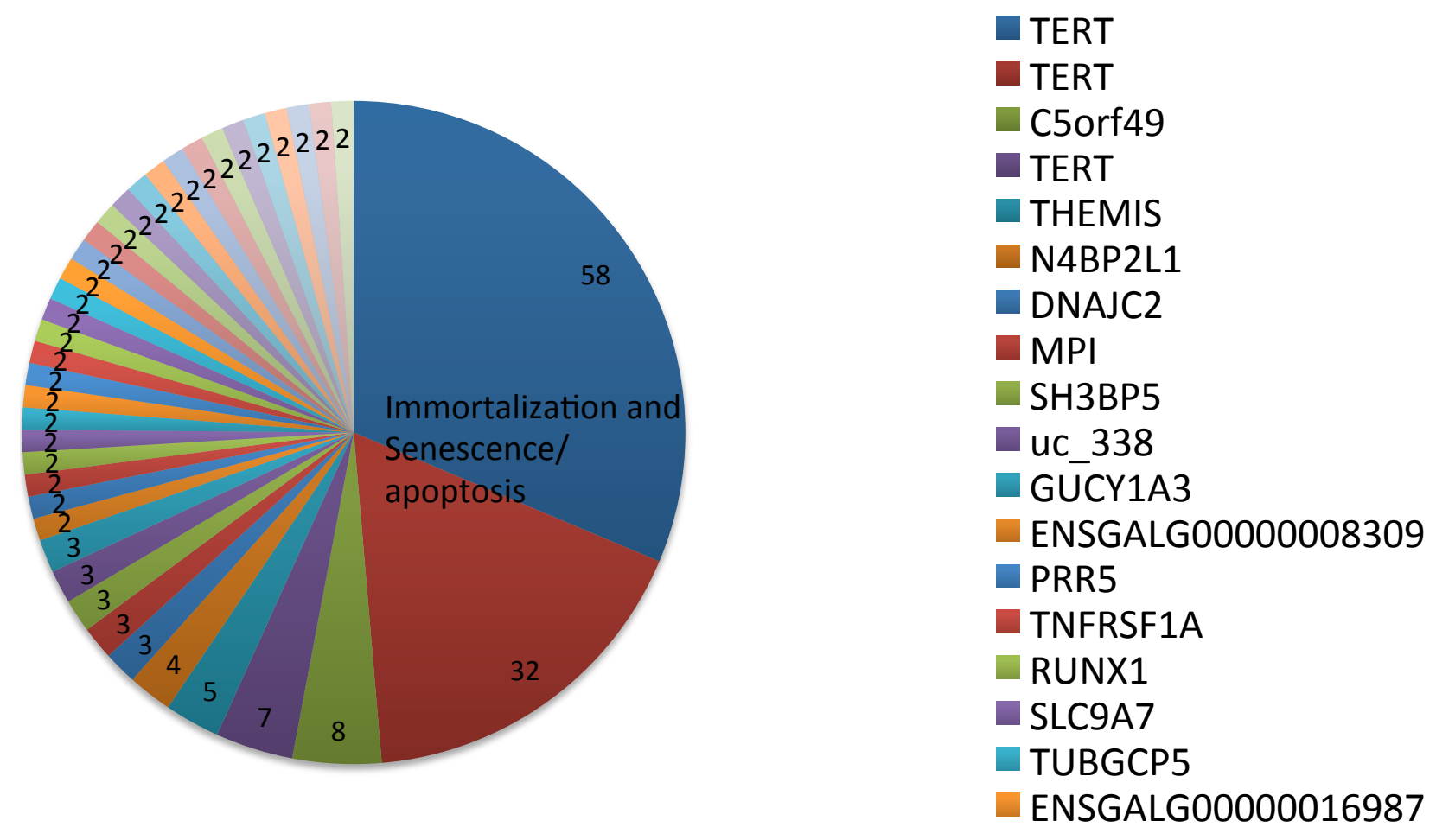




\section{D2B Tumor}

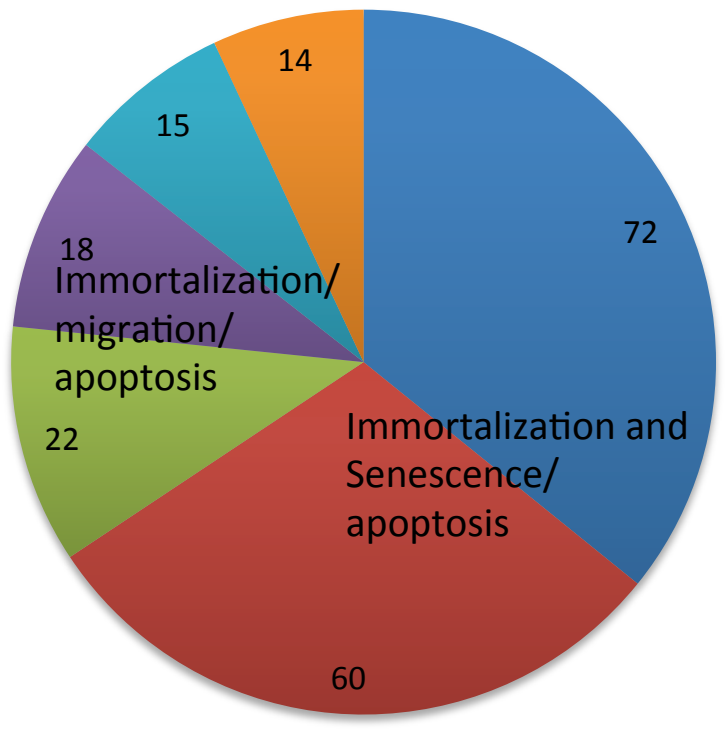

- TERT

- TERT

CTDSPL1

- CTDSPL2

CTDSPL2

REPS2 


\section{D4B Tumor}

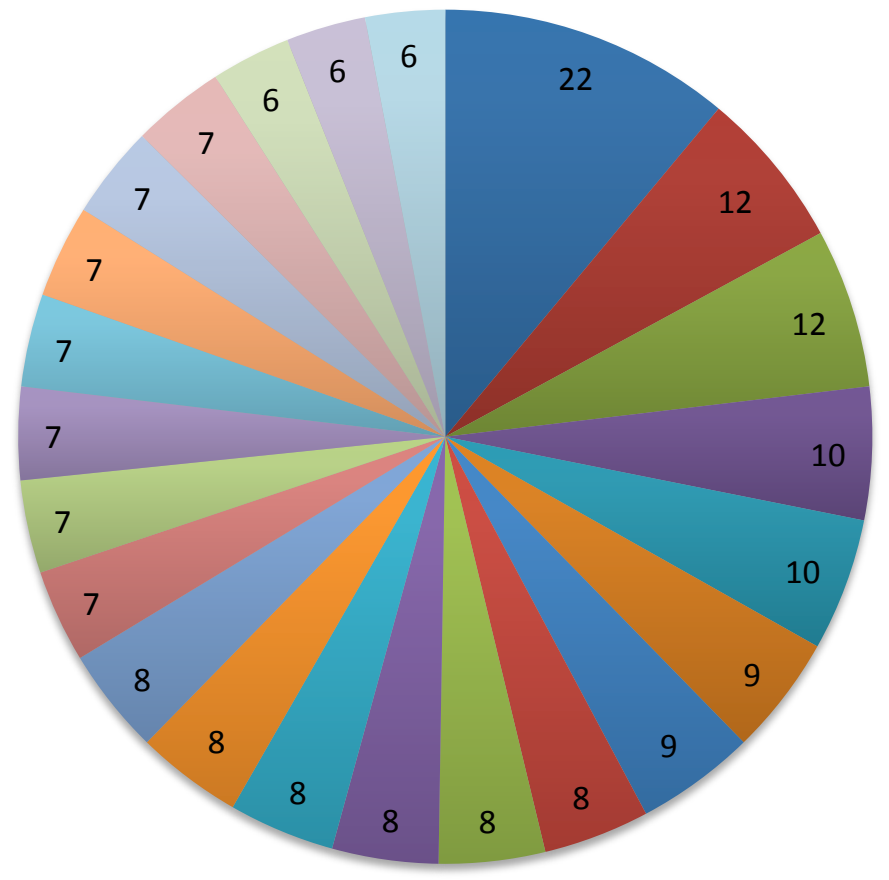

CZH5ORF44

- IKZF1

ENSGALT00000032334

TNFRSF1A

CHD2

TIAM1

ENSGALT00000045904

KAL1

SNX10

ENSGALT00000040625

CAMSAP2

PPM1L 


\section{D5B Tumor}

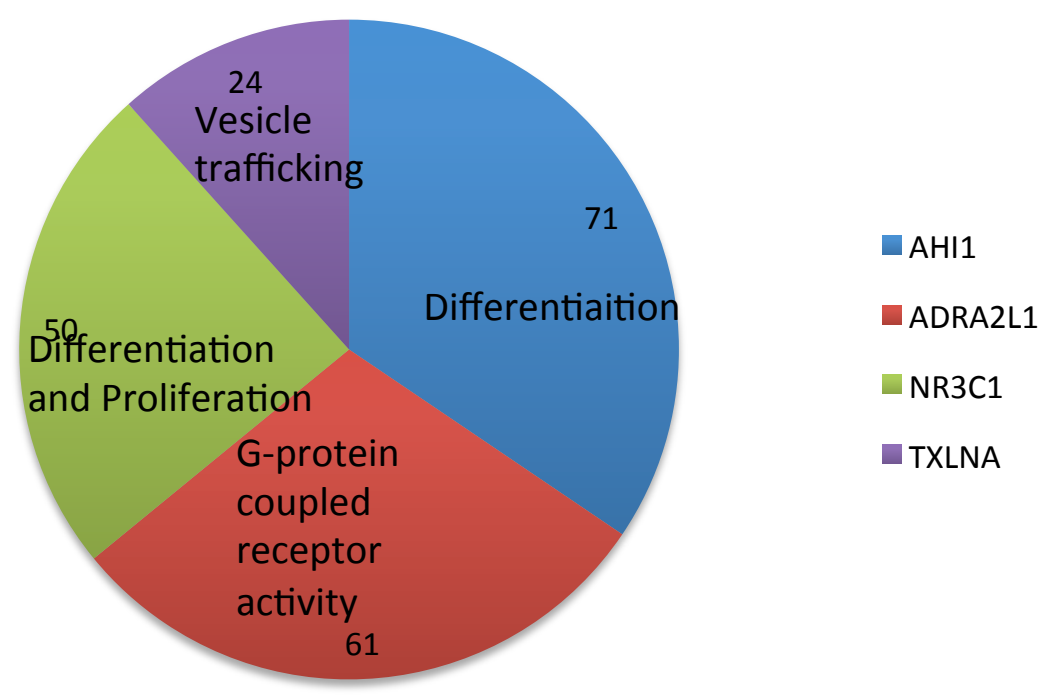




\section{D7B Tumor}

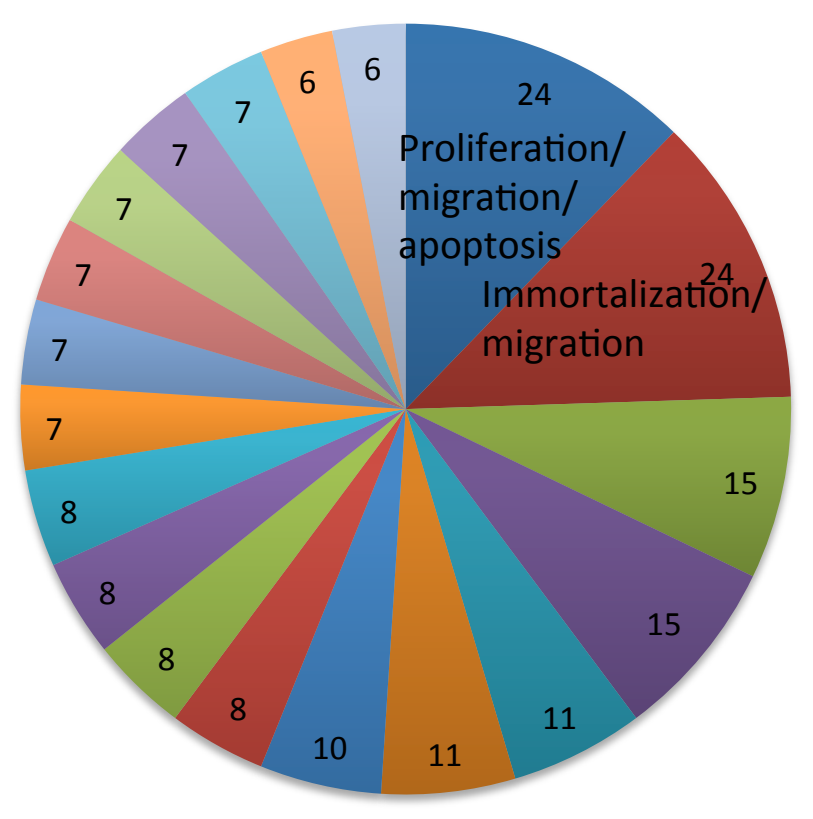

MCTS1

CTDSP1

TCEA1

ENSGALT00000045195

- TMPO

RUNX1

- IAP3

- TNFRSF1A

TNFRSF1A

ENSGALG00000002208

ARID4B

APBB1IP

PIP4K2A

MYBL2

ENSGALG00000009055

- CETN3

NT5DC3

ENSGALT00000020783 


\section{D9B Tumor}

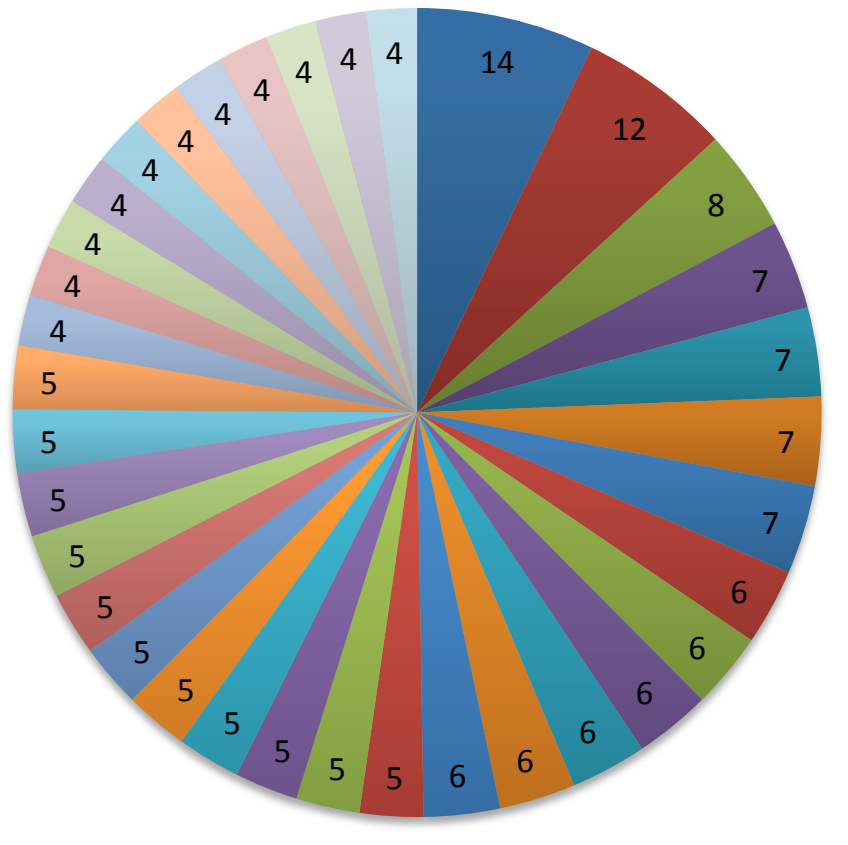

ITGA6

DUSP22

ENSGALT00000045044

GRIN2B

DHCR24

CHST2

ST8SIA4

ATXN7L1

C3H6ORF72

ENSGALT00000025160

PDE3B

$A B \mid 2$

DOCK8 


\title{
D8B Tumor
}

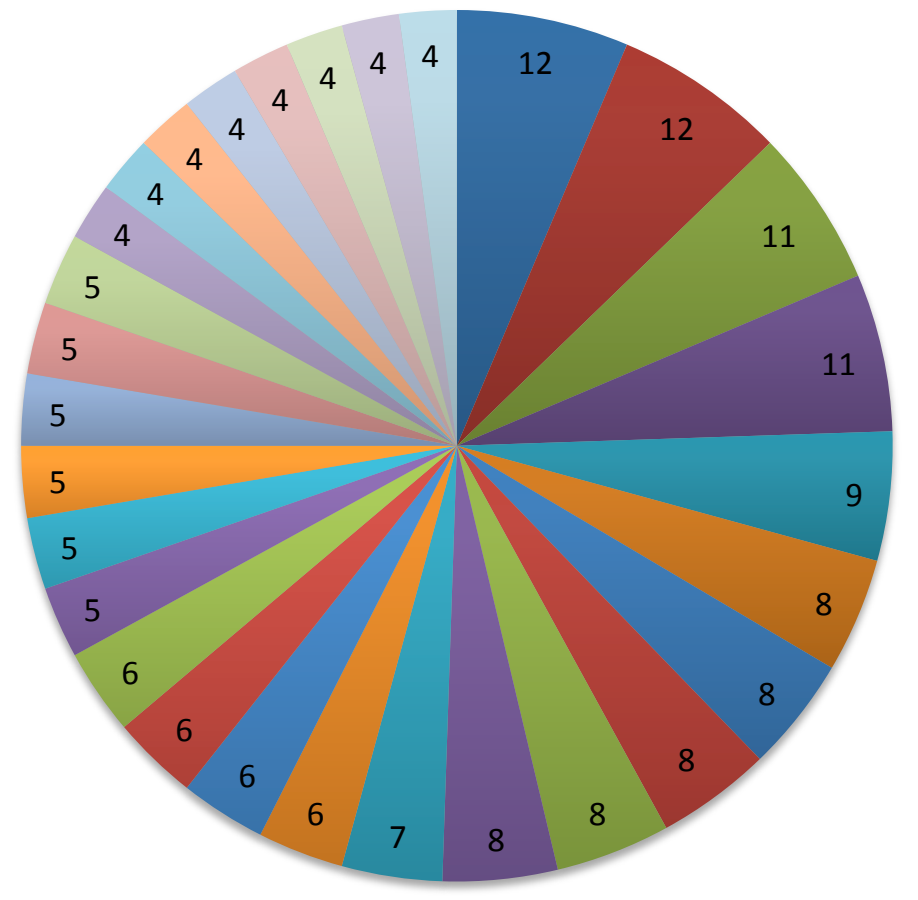

\author{
- SLC4A7 \\ NFKB1 \\ TRAK2 \\ Q Q8QH06_CHICK \\ DNAJC6 \\ RASA3 \\ - RASA3 \\ DSEL \\ - SLC16A14 \\ - H4_CHICK \\ unannotated \\ unannotated
}




\section{E5B Tumor}

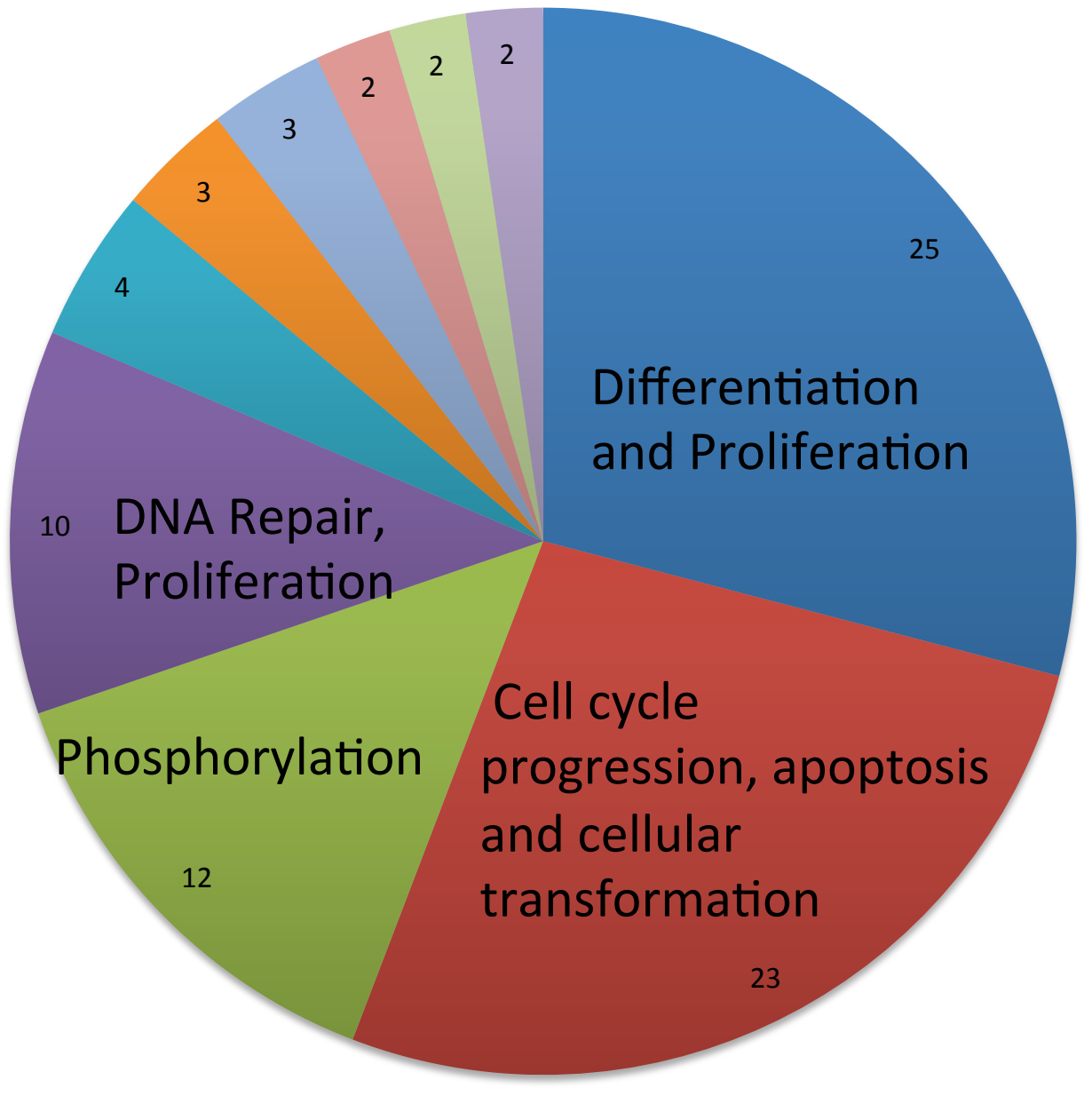

C-MYB

MYC

DCAKD

HELLS

$\mathrm{CDH} 2$

KCNH8

TSSC1

PHYHIPL

$\mathrm{CDH} 20$

ENSGALG00000015528 


\section{F1B Tumor}

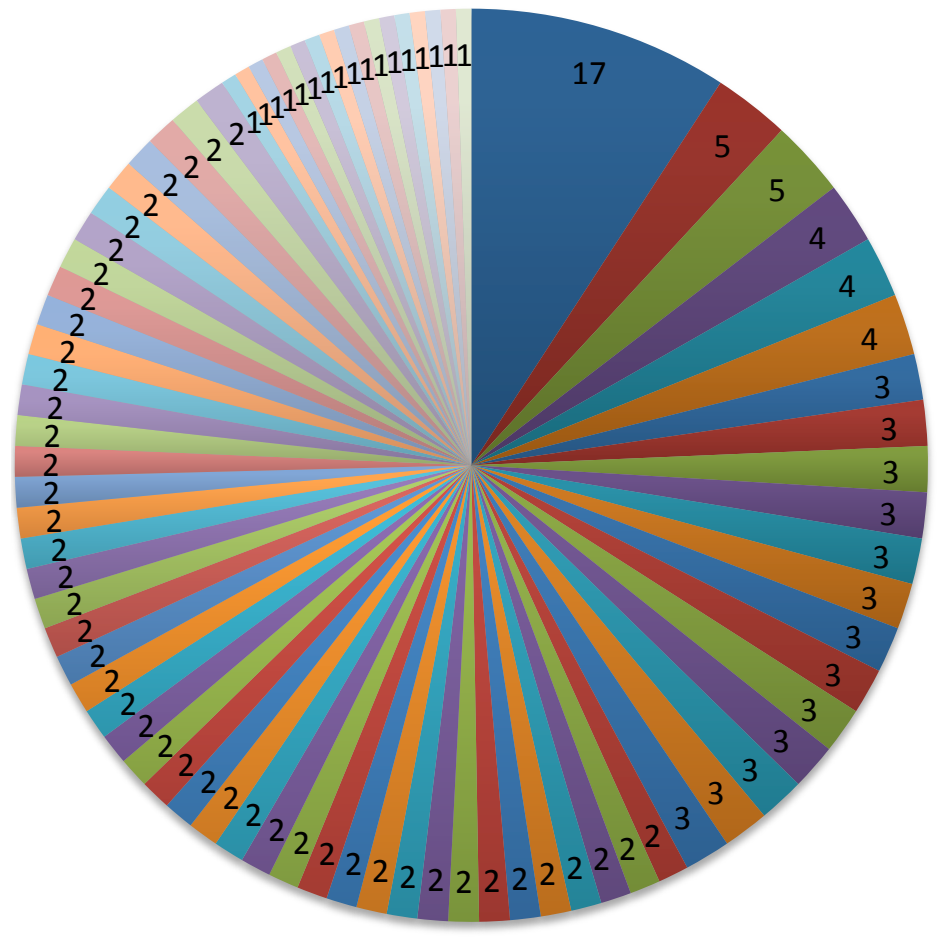

MCTP1

GWL

Q98TX6

- F1NYZ1

DPY30

unannotated

GNAI1

- IFRD1

BTBD11

- CDC91

-TNFRSF1A

unannotated 


\section{F2B Tumor}

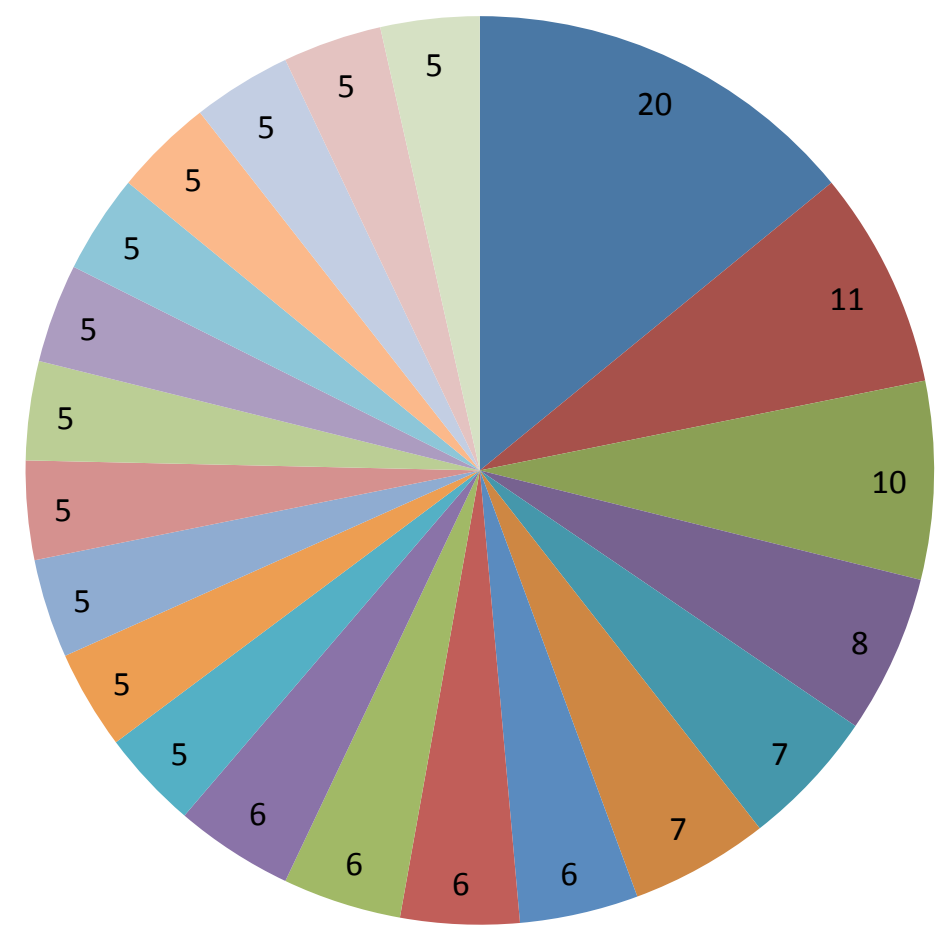

- ZFY (Homo sapiens) - protein_coding

protein_coding

TMPO (Homo sapiens) - Q5ZKG7_CHICK

Q5F4B0_CHICK

HOGA1

MISMAPPED (TNFRSF1A by Blast) - PFDN52

Q Q5ZMW1_CHICK

- TNFRSF1A (Homo sapiens) - Q5ZJG1_CHICK

NCAPG2

-F1NA76_CHICK

protein_coding

E1BZD6_CHICK

protein_coding 


\section{F3B Tumor}

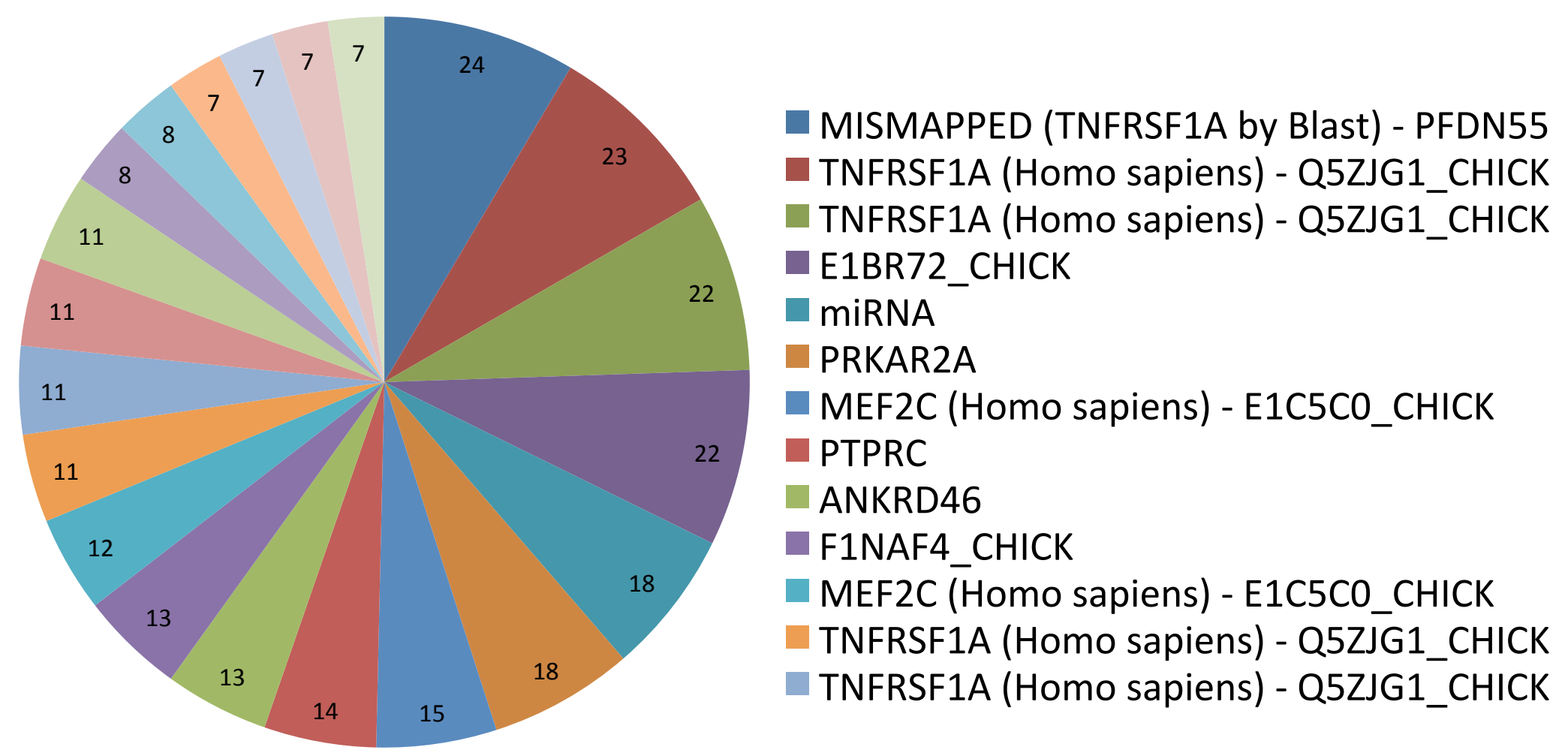




\section{F4B Tumor}

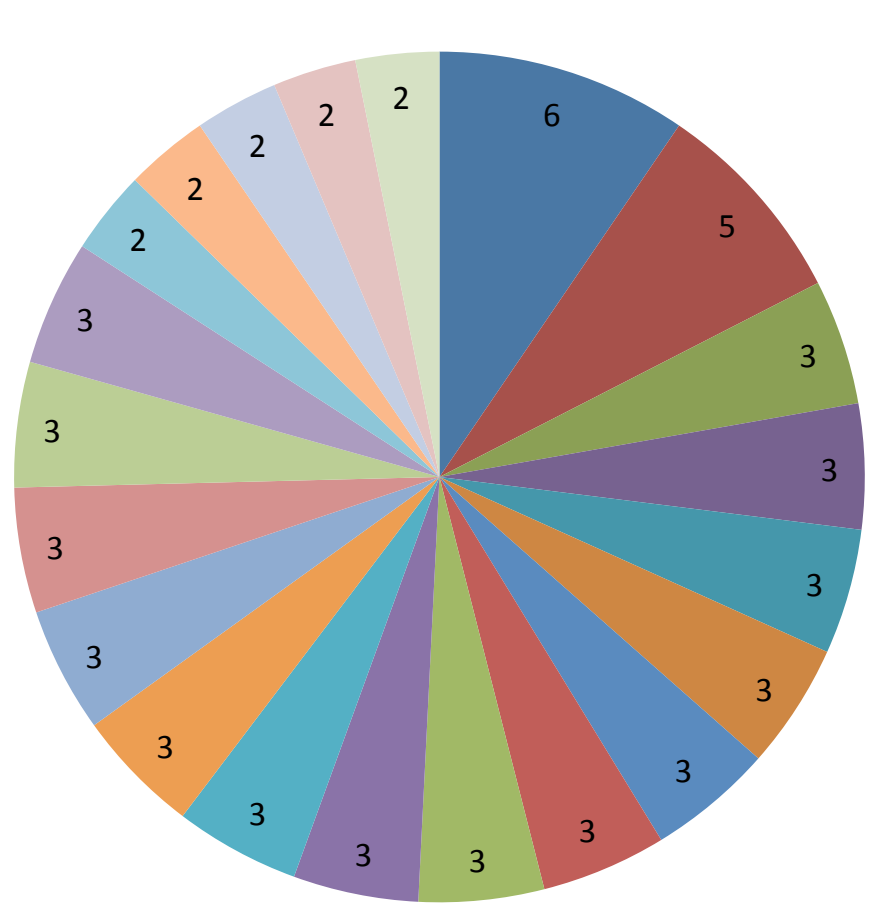

- FGD6

QQ9W6J2_CHICK

LAMB1

- ANKRD10 (Homo sapiens) - ANR10_CHICK

RBM26

-F1NST2_CHICK

GAA

- SRSF1

RNASEN

NSMCE2

MAN1A1

LPIN1

IF4G2_CHICK 


\section{F5B Tumor}

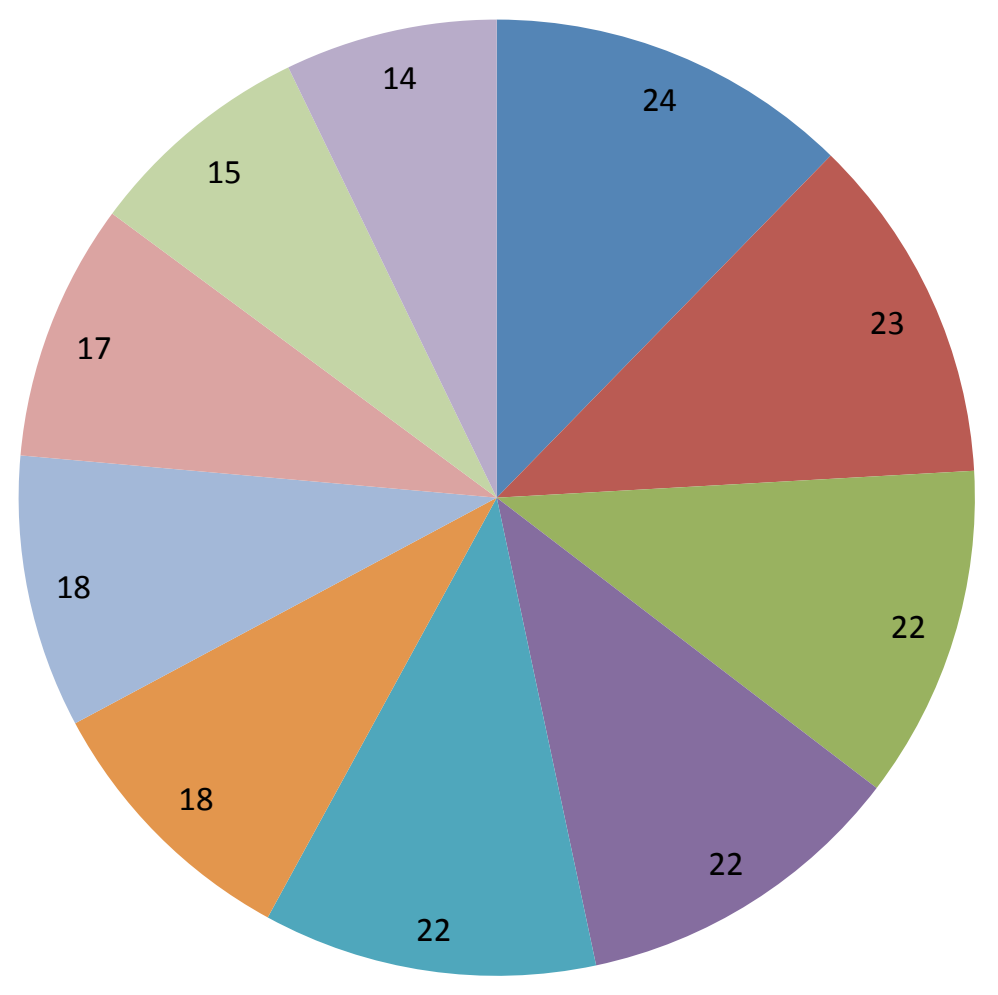

MISMAPPED (TNFRSF1A by Blast) - PFDN55

- TNFRSF1A (Homo sapiens) - Q5ZJG1_CHICK

RERE

TNFRSF1A (Homo sapiens) - Q5ZJG1_CHICK

E1BR72_CHICK

miRNA

PRKAR2A

$\square$ TULP3

MEF2C (Homo sapiens) - E1C5CO_CHICK

ANKS6 
Liver 


\section{A2L Tumor}

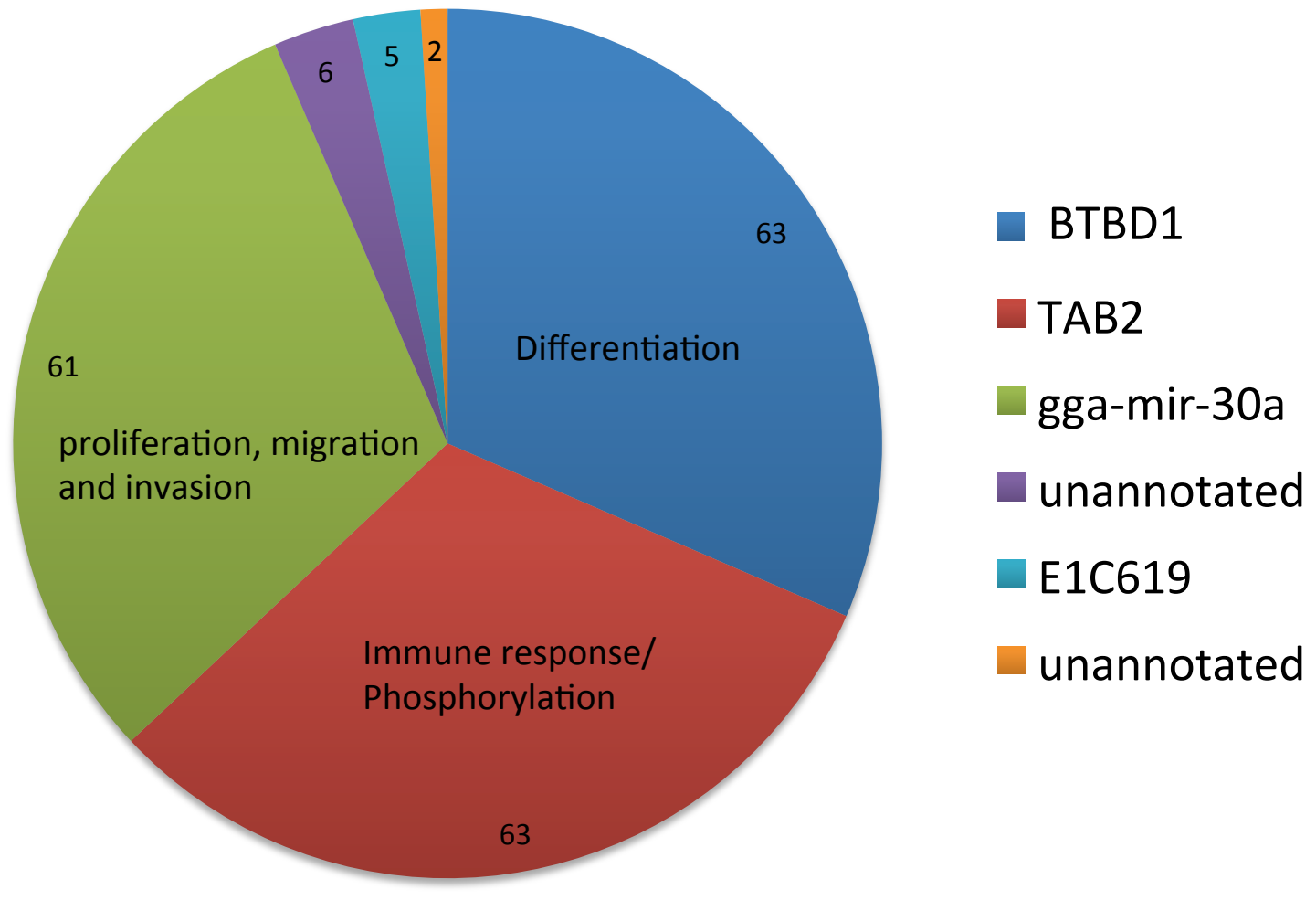




\section{A4L Tumor}

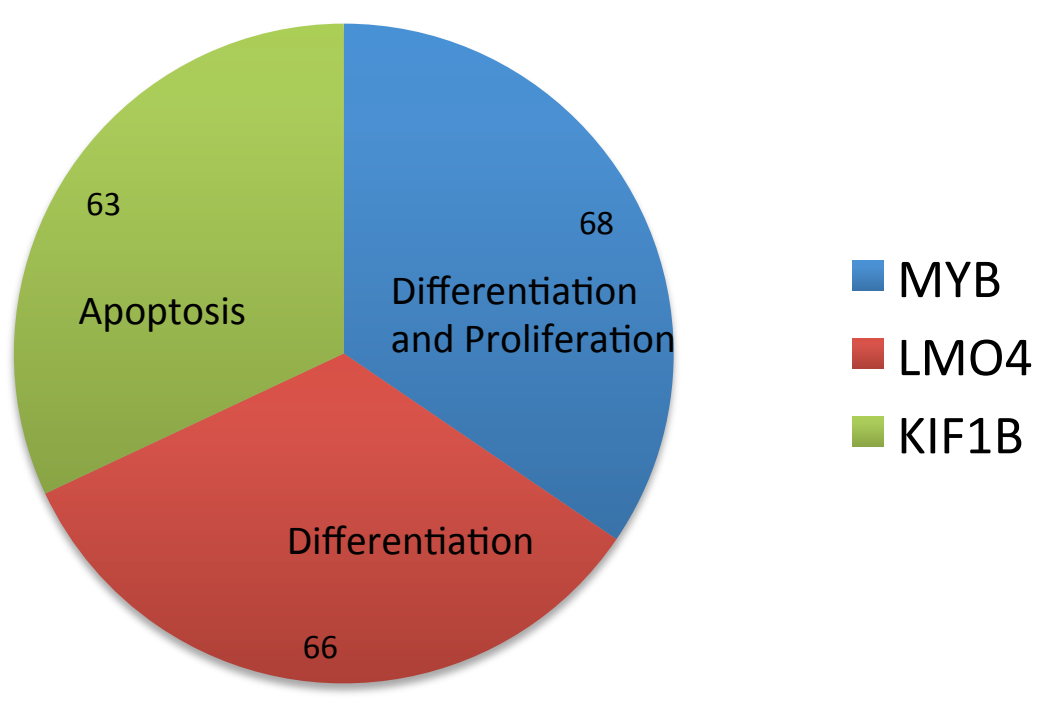




\section{A5L Tumor}

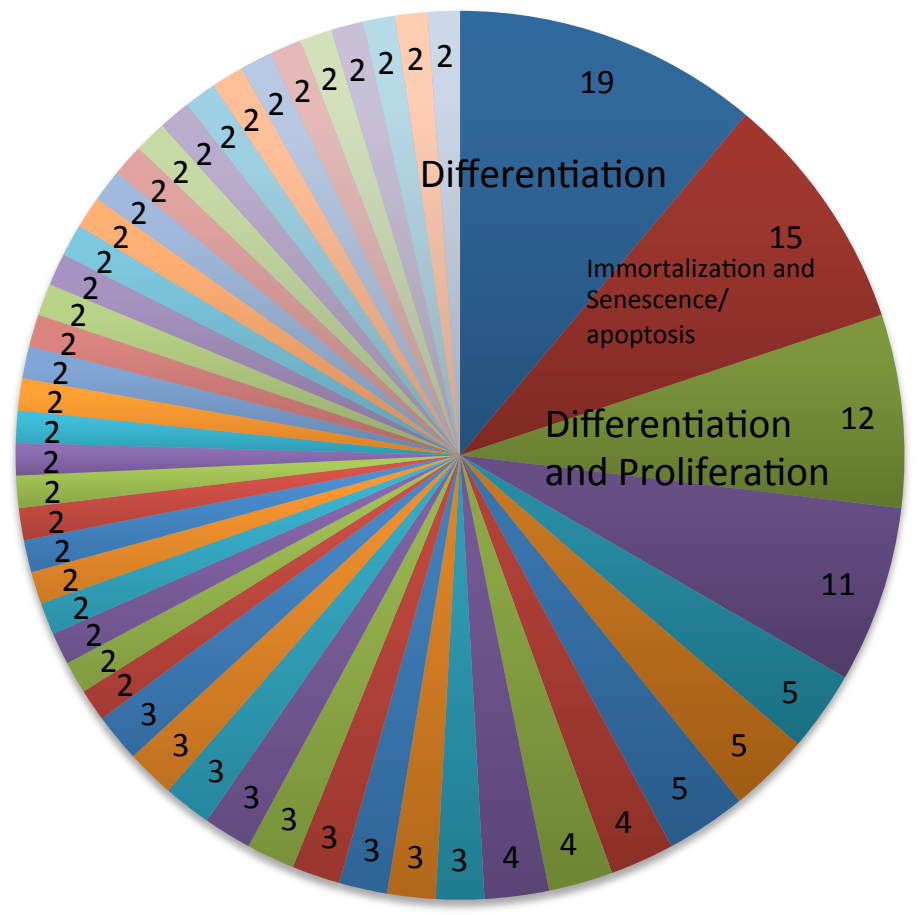

ENSGALT00000030764

AHI1

TERT

MYB

gga-mir-222a

ENSGALT00000045995

MYB

gga-mir-155

UBL3

ambiguous

ENSGALG00000026370

WTIP 


\section{C2L Tumor}

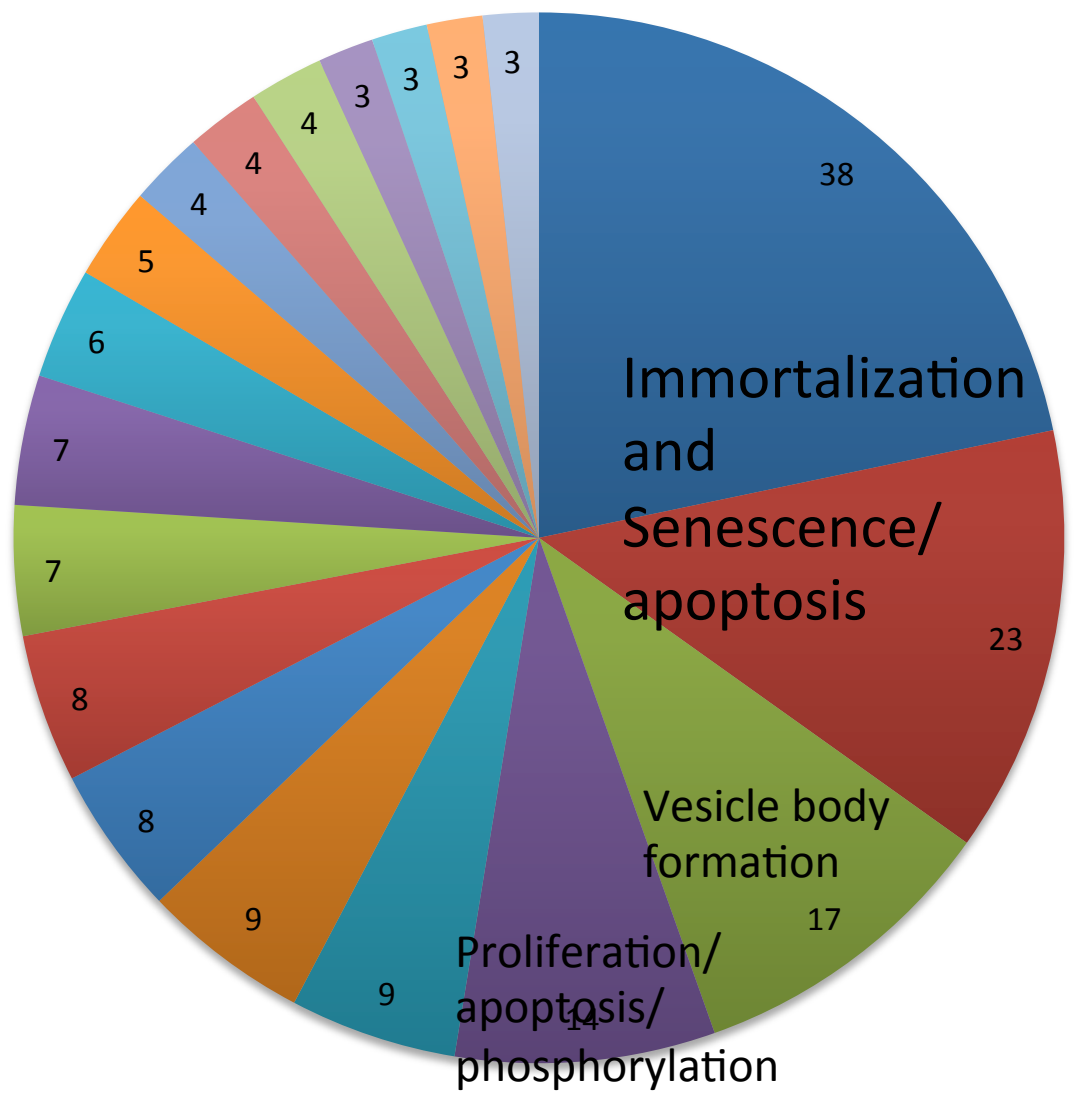

TERT

TERT

CHMP2B

AKT1

- LRRC8C

FBXO3

AP4S1

NAT13

gga-mir-222

F1P0B9

BPNT1

PROX1

CCDC85C

unannotated

E1C6S5 


\section{C3L Tumor}

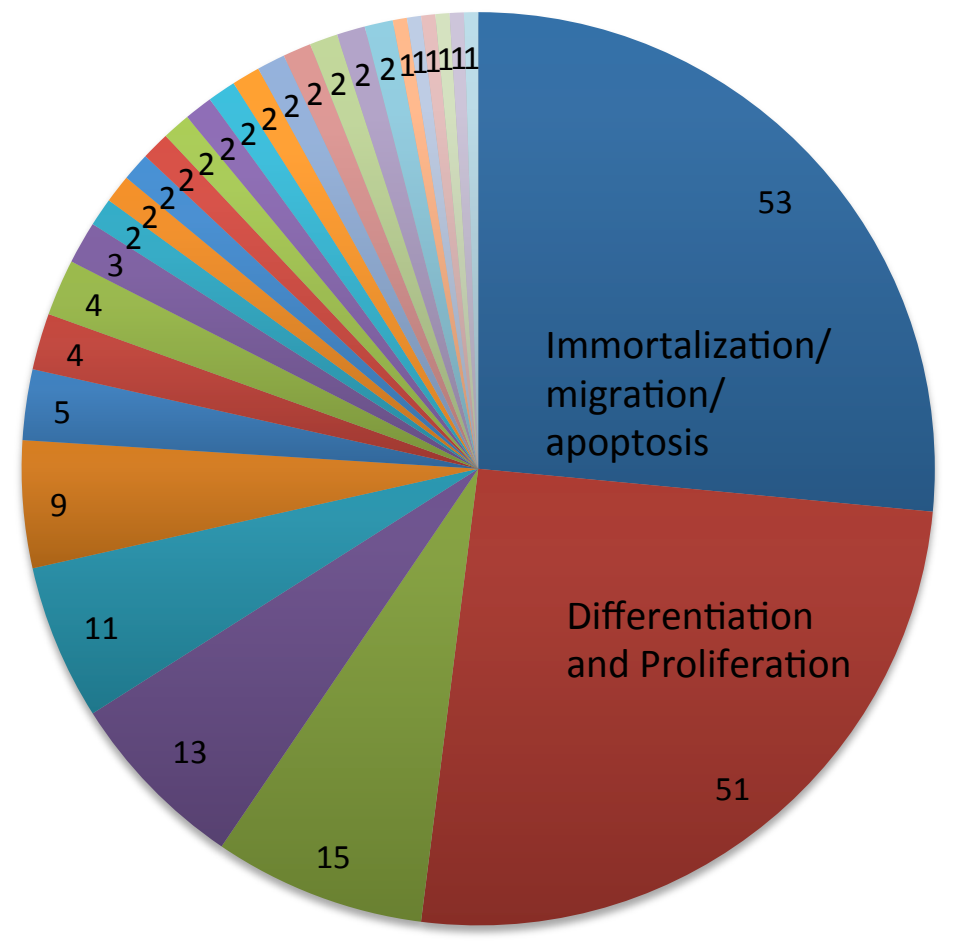

- CTDSPL

- MYB

ATP11B

- gga-mir-155

F1NN52

CTDSPL2

STAU2

gga-mir-155

CTDSPL2

TOX

HMGB1

CTDSPL2

- IQSEC1 


\section{C4L Tumor}

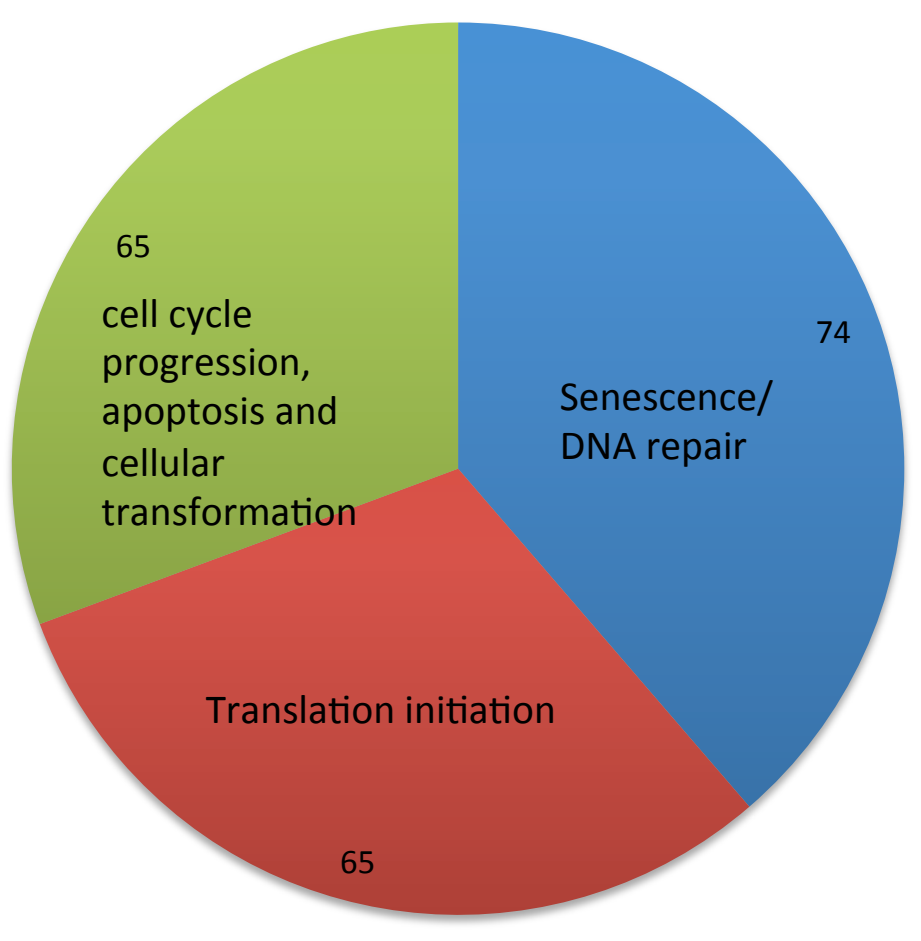

POT1

EIF4E

MYC 


\section{C6L Tumor}

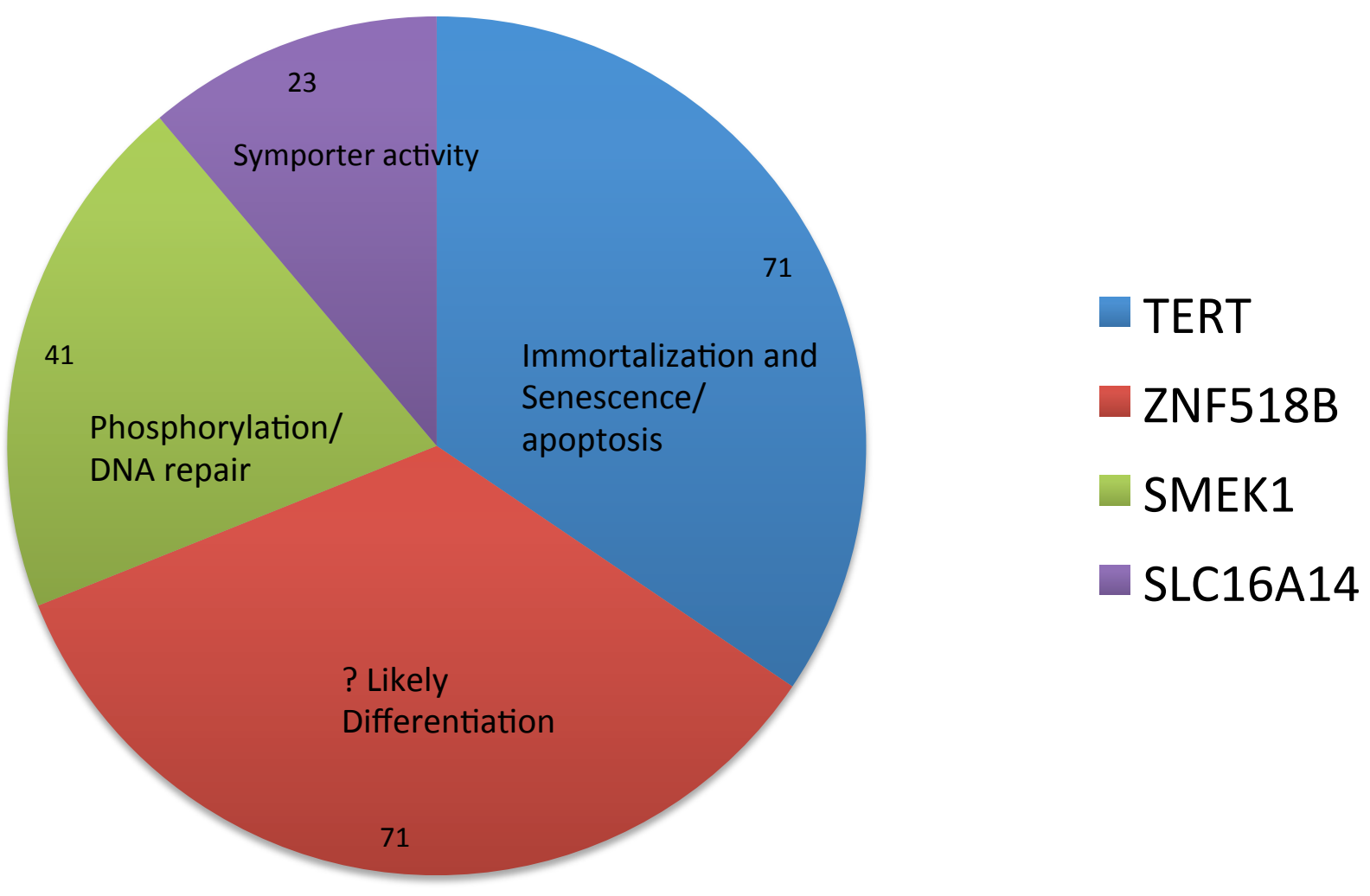




\section{C7L Tumor}

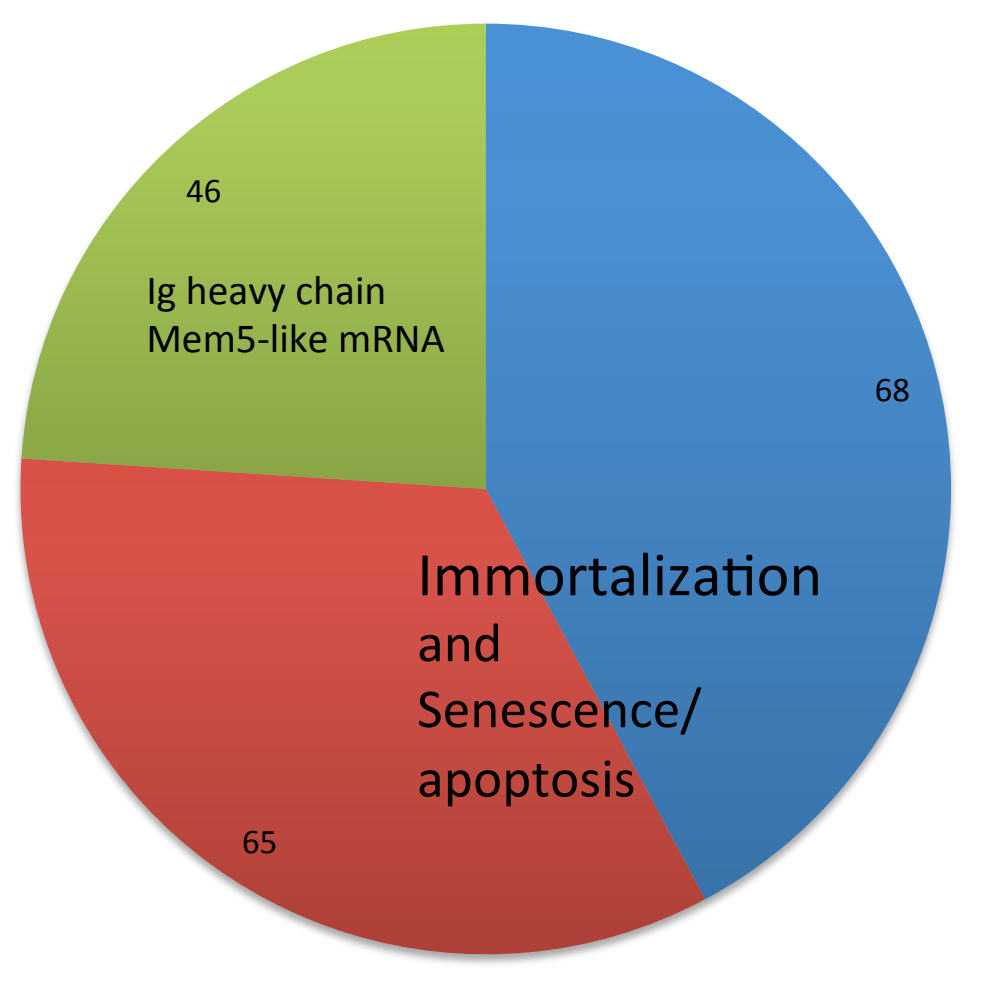

TERT

- TERT

- LOC769232 


\section{D5L Tumor}

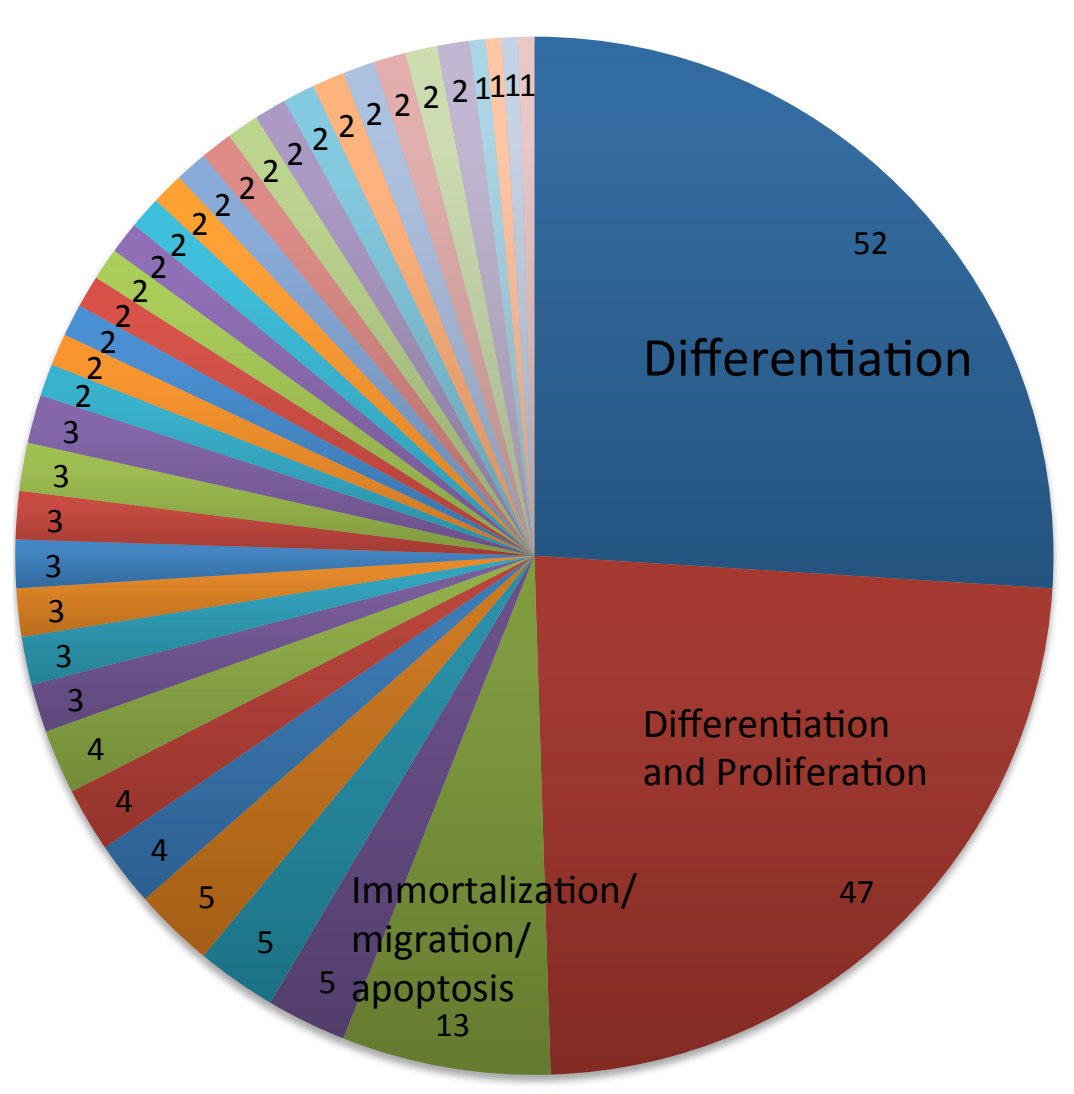

AHI1

F1N9Z5

CTDSPL

TXLNA

PPFIA1

$\mathrm{SIAH} 2$

TOX

PARP1

MYB

E1BWK1

unannotated

F1NKV4

IKZF1

EFCAB4A

TRIM3

- S2546_CHICK

TTC26 


\title{
D2L Tumor
}

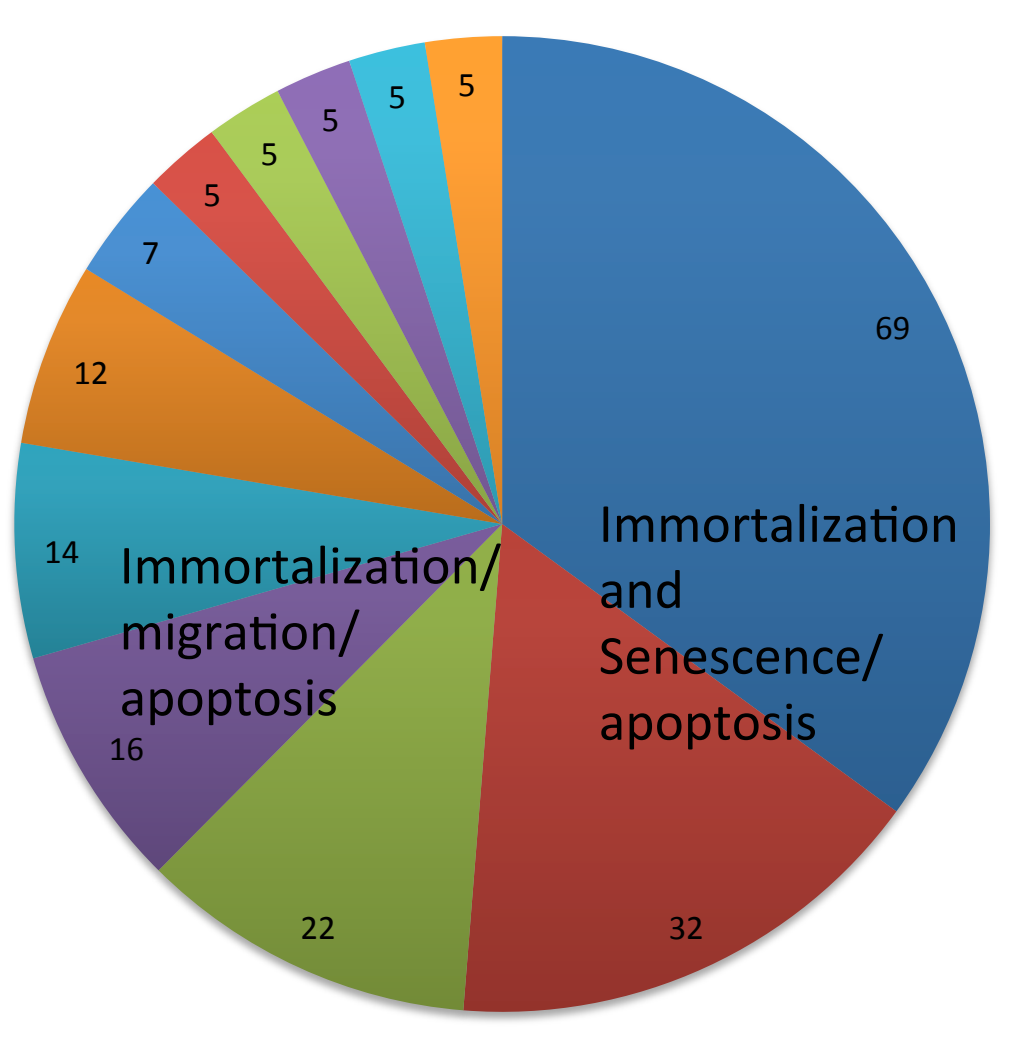

\author{
- TERT \\ - TERT \\ CTDSPL \\ CTDSPL \\ - CTSL2 \\ - CTSL2 \\ CXorf57 \\ gga-mir-155 \\ CTDSPL \\ - CTDSPL \\ gga-mir-216 \\ ACOT9
}




\title{
F6L Tumor
}

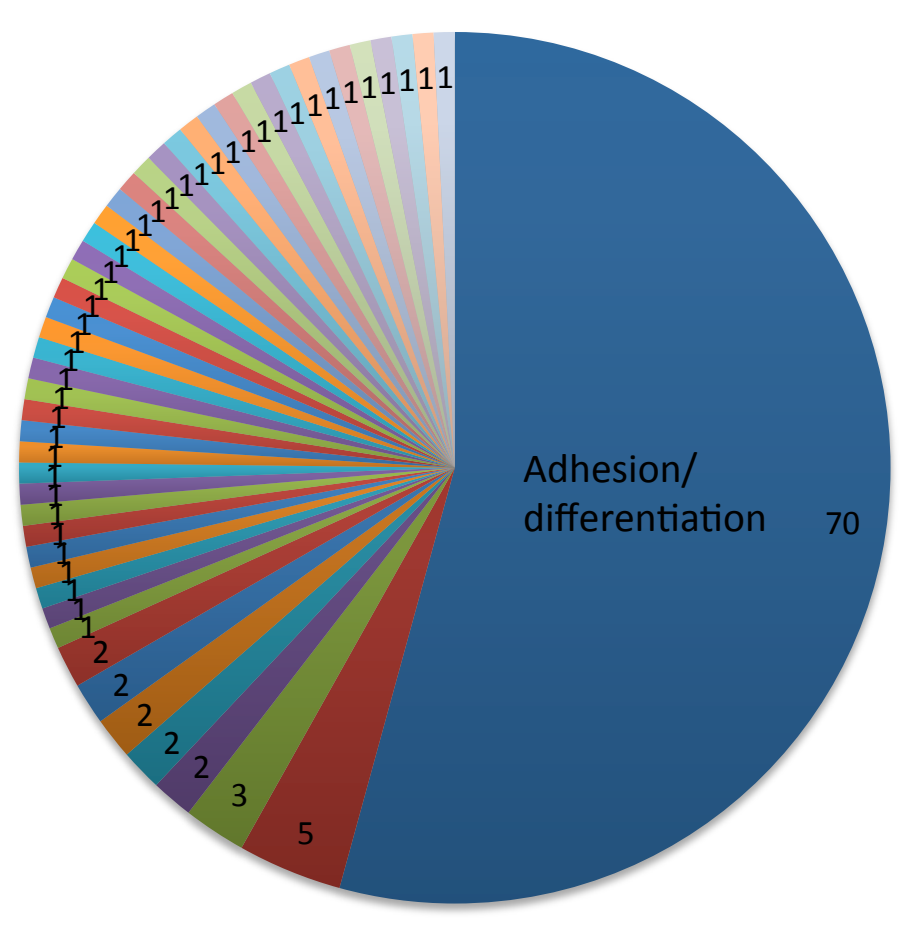

\author{
- TNR \\ - LAS1L \\ Q5F4A2 \\ PUF60 \\ MYB \\ SHOC2 \\ TNR \\ E1C619 \\ ATP6AP1 \\ - PPFIBP1 \\ BBX \\ Q6XFR0 \\ F1NCR4 \\ - CXADR \\ ITGBL1 \\ ALG8 \\ ARFIP2
}




\section{F7L Tumor}

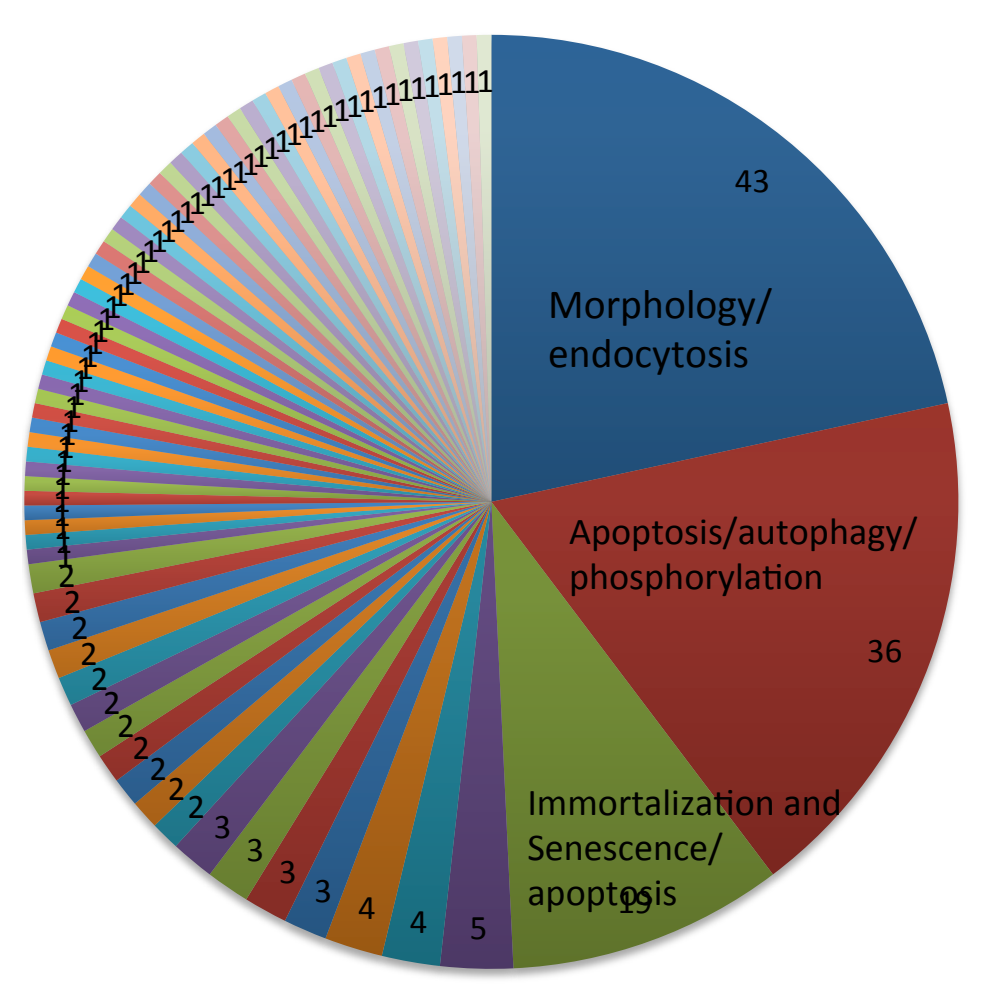

Q Q5ZLN3

aAF1

- TERT

ELF1

SERINC2

TNFRSF1A

FAM107B

073609

E1BZP4 


\section{E1L Tumor}

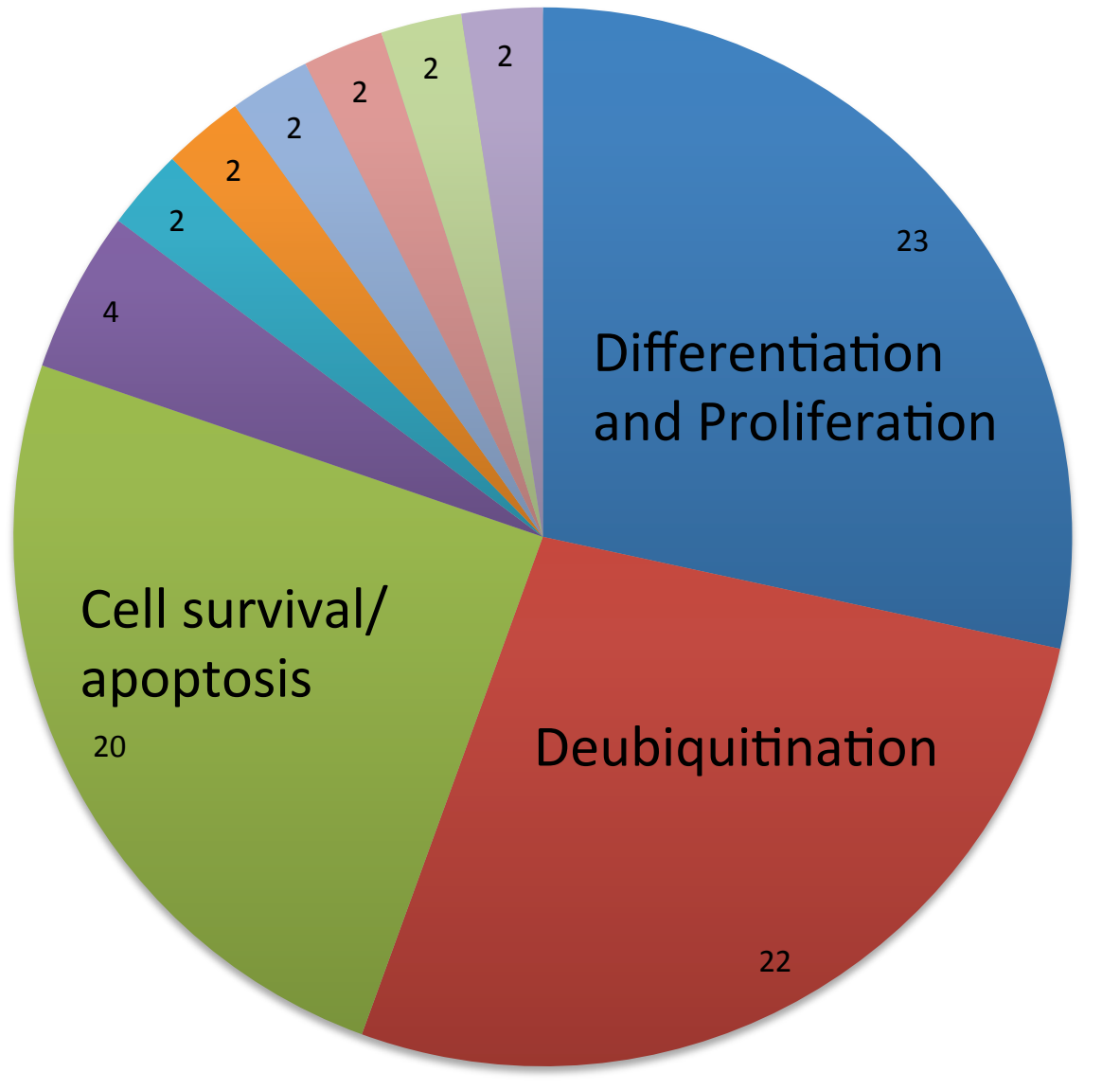

C-MYB

STAMBPL1

gga-mir-155

RFX4

GAB1

- FCHO1

MA8

uc-338

ENSGALG00000006075

PSMB1 


\section{E2L Tumor}

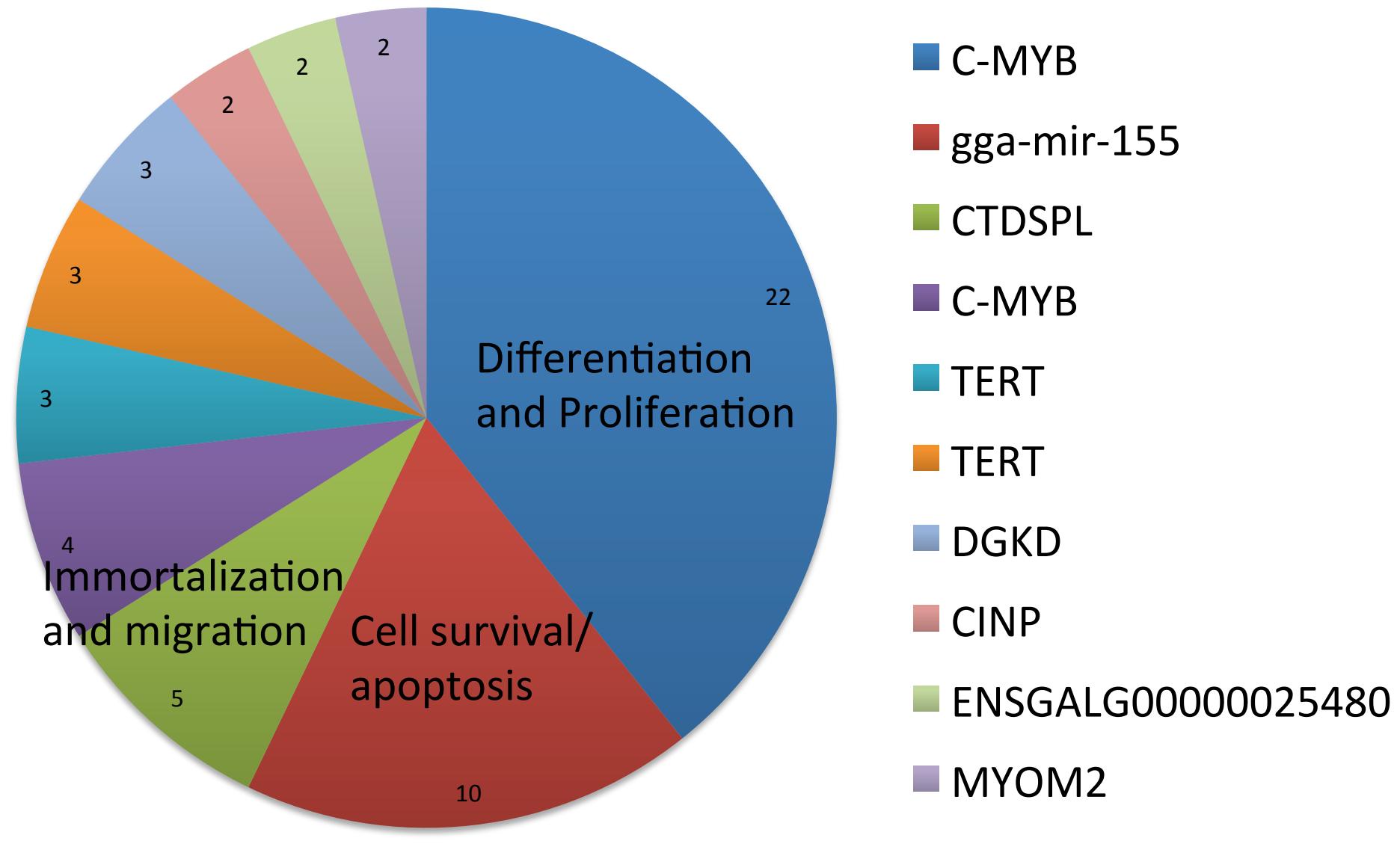




\section{E3L Tumor}

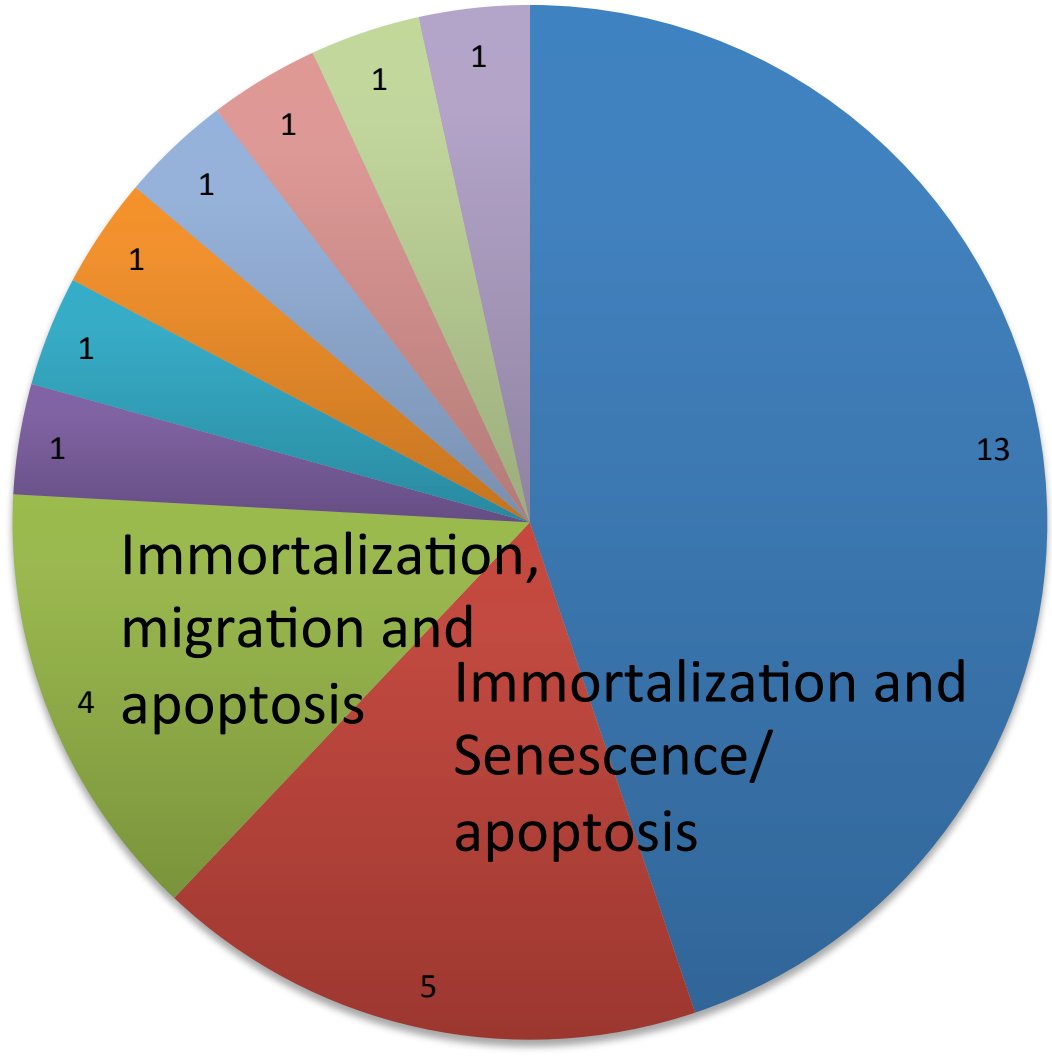

TERT

- TERT

CTDSPL2

ARGHGAP32

ACAA2

FTO

ENSGALG00000003619

GOSR1

PRKCB 


\section{E4L Tumor}

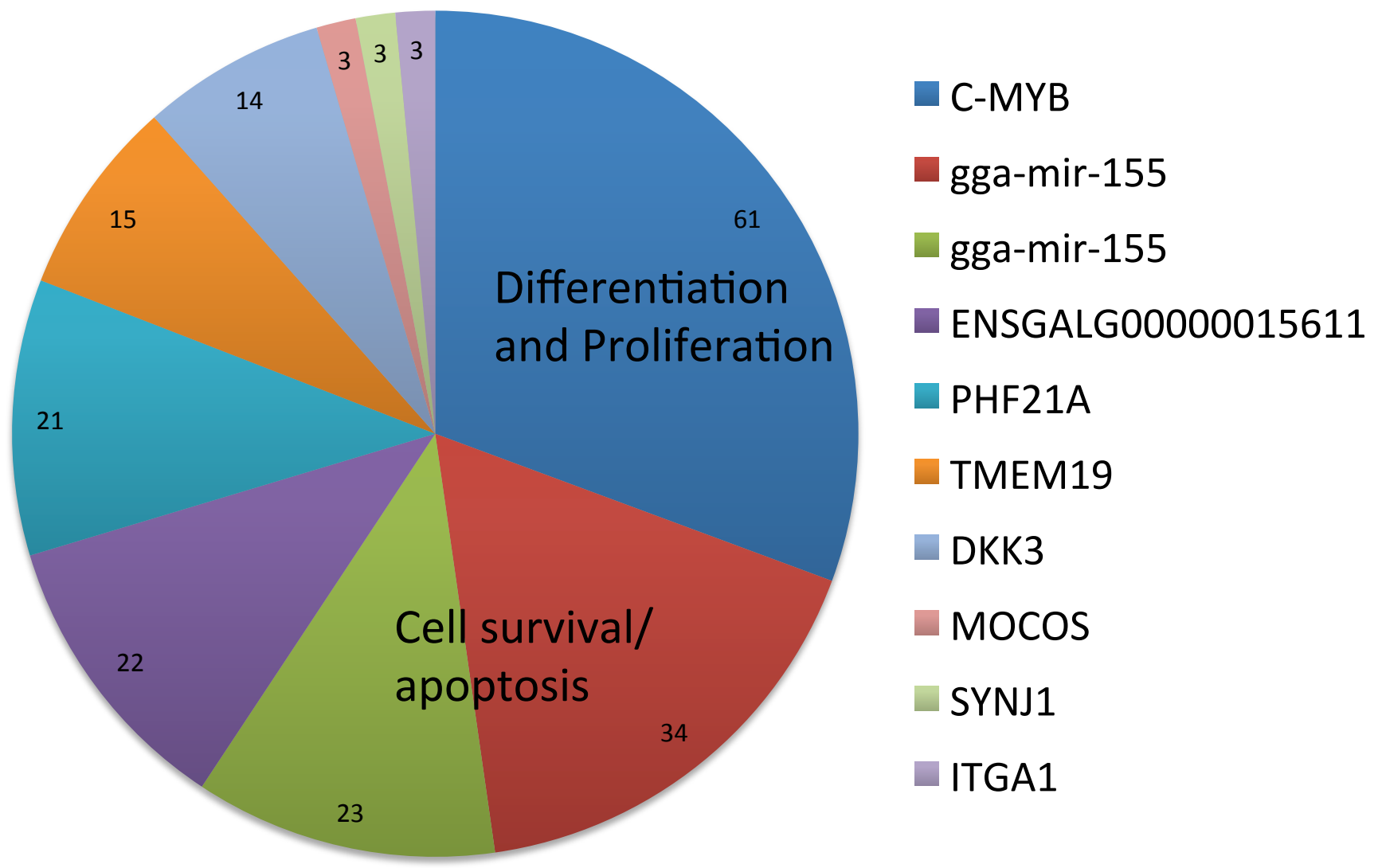


Spleen 


\section{A2S Tumor}

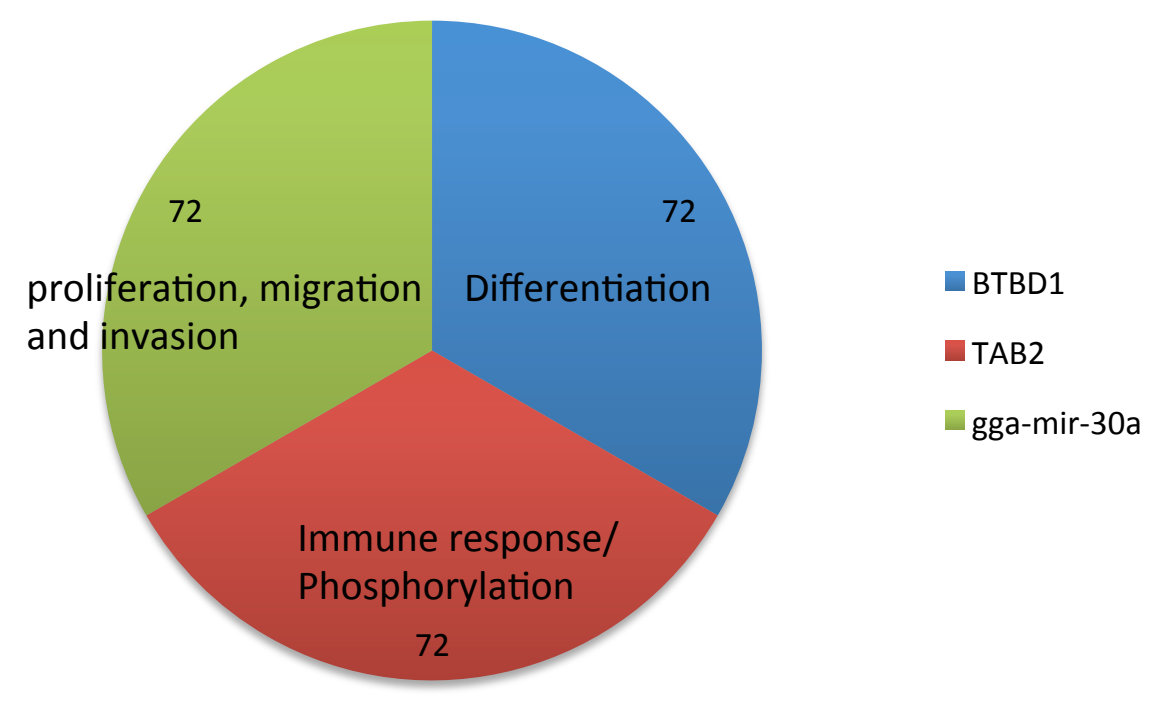




\section{A6S Tumor}

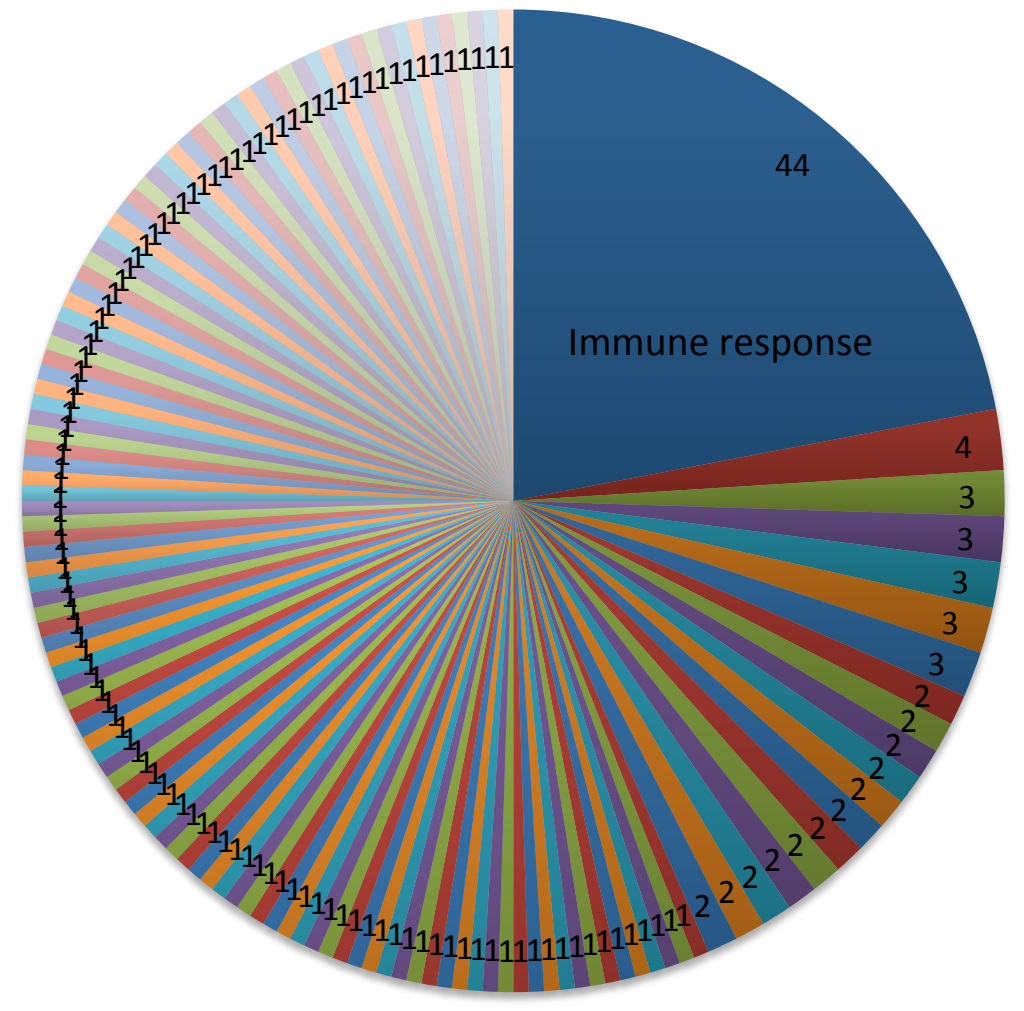

FAM19A2

NTN1

MYB

PIK3R5

MYB 


\title{
C2S Tumor
}

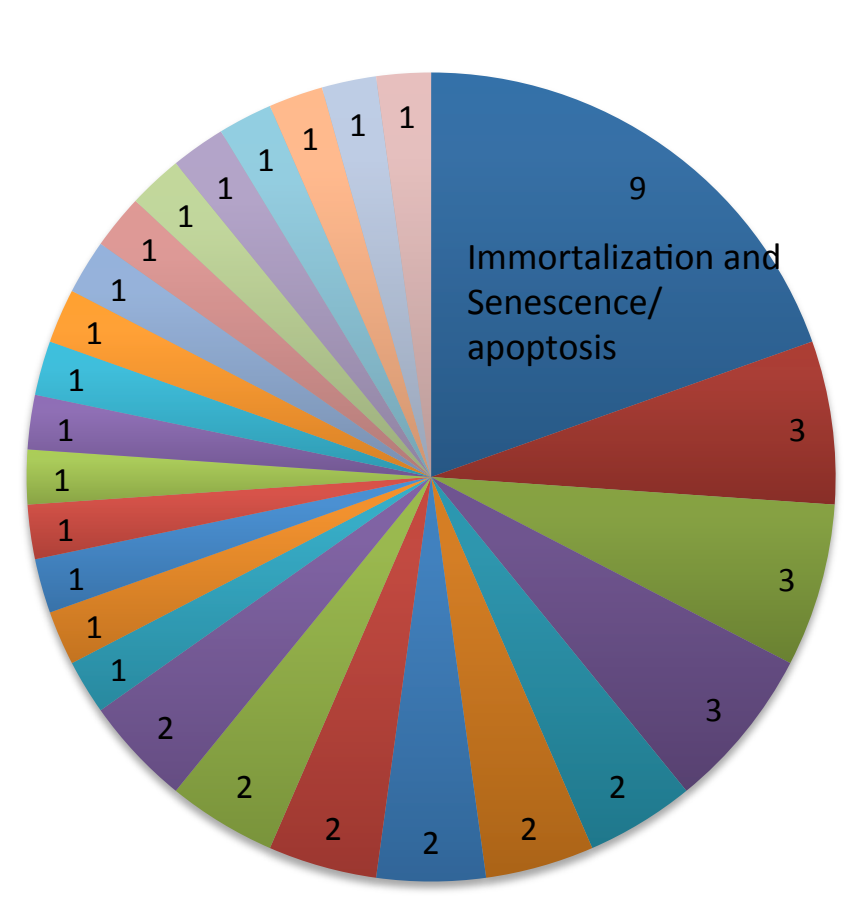

\author{
- TERT \\ ENSGALG00000008054 \\ RUNX2 \\ ZDHHC5 \\ ENSGALG00000007107 \\ - JADE2 \\ TERT \\ SEH1L \\ PM20D1 \\ MOSPD1 \\ ENSGALG00000009771 \\ ENSGALG00000027884 \\ CYTH4 \\ XPO4 \\ SALL3
}




\section{C4S Tumor}

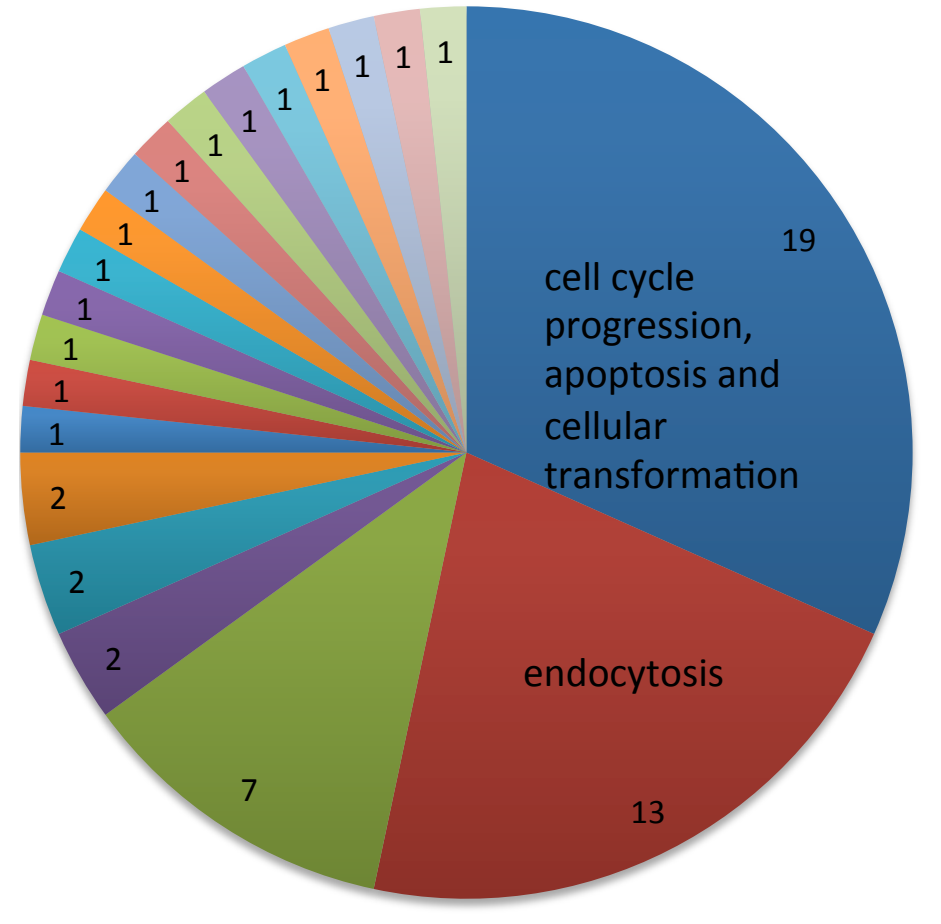

MYC

- ITGB6

CXorf57

CXorf57

- EIF4E

ENSGALG00000028071

CXorf57

CXorf57

KIAA0232

ENSGALG00000013155

TSHZ2

DIP2C

gga-mir-92

ENSGALG00000025503

POLR3B

HIPK2 


\section{D5S Tumor}

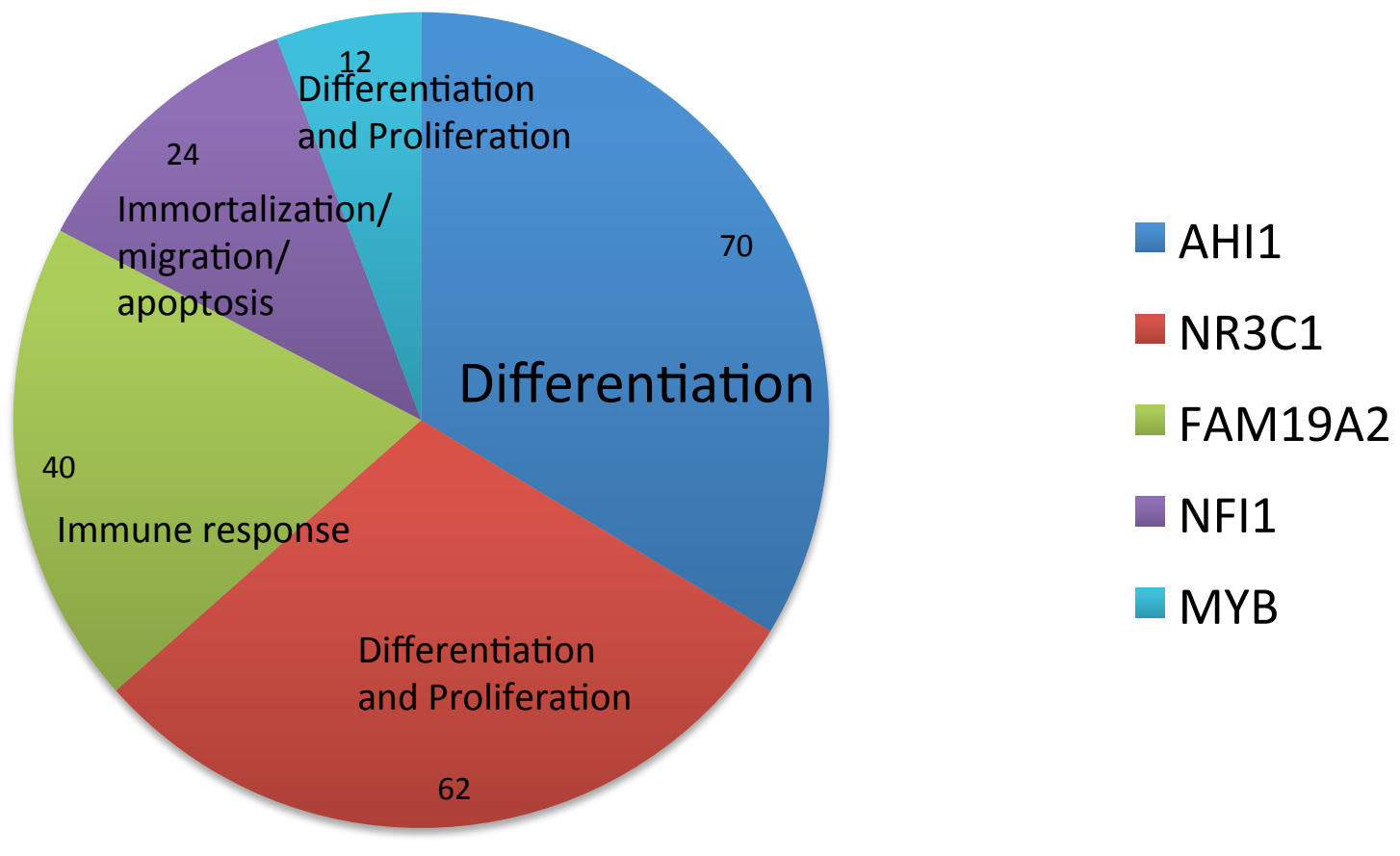




\section{F8S Tumor}

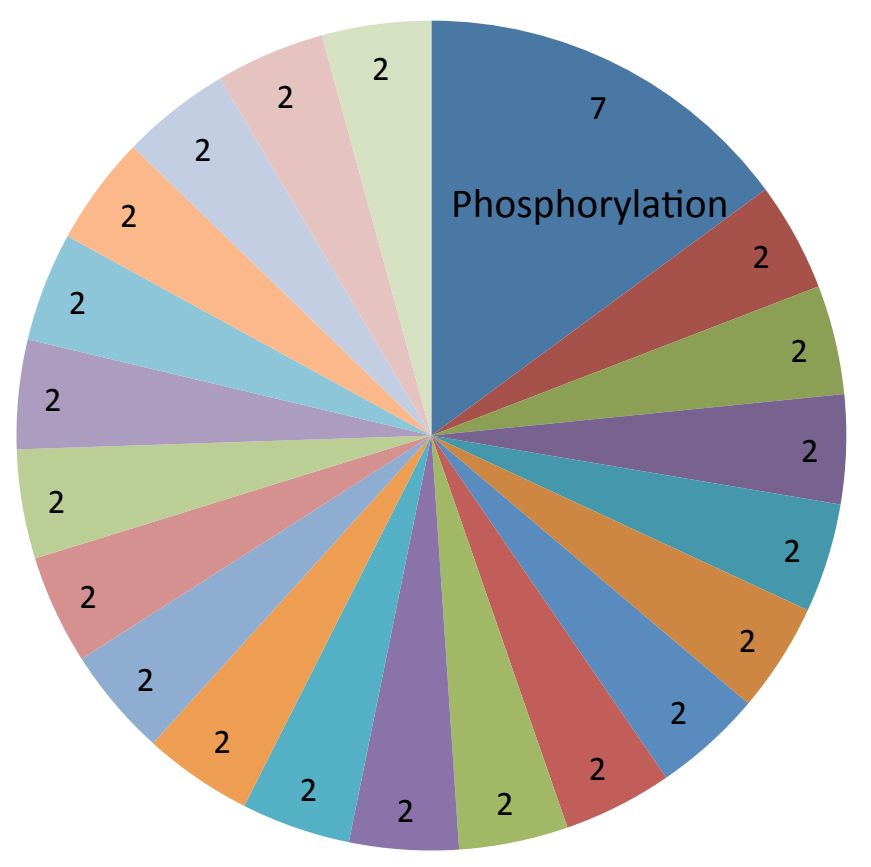

- PLCH2

GRAMD4

LTA4H

protein_coding

ADAMTS1

SH3RF3

protein_coding

E1C080_CHICK

protein_coding

ABHD6

TOM1L2

TNRC6A 
Kidney 


\section{A2K Tumor}

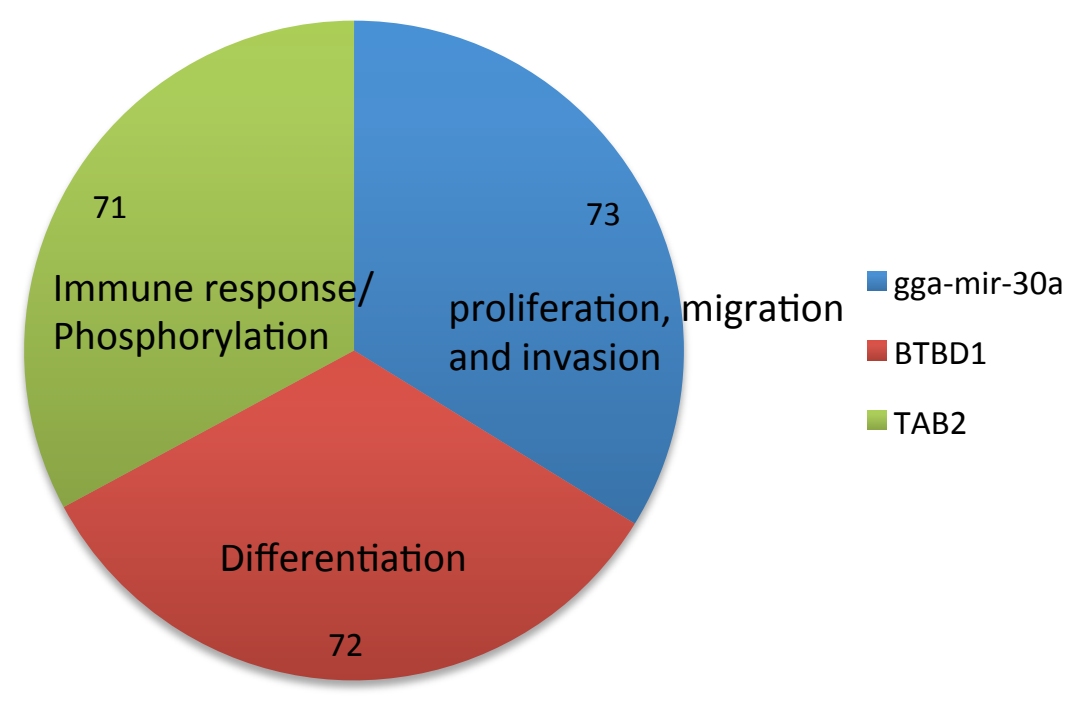




\section{C3K Tumor}

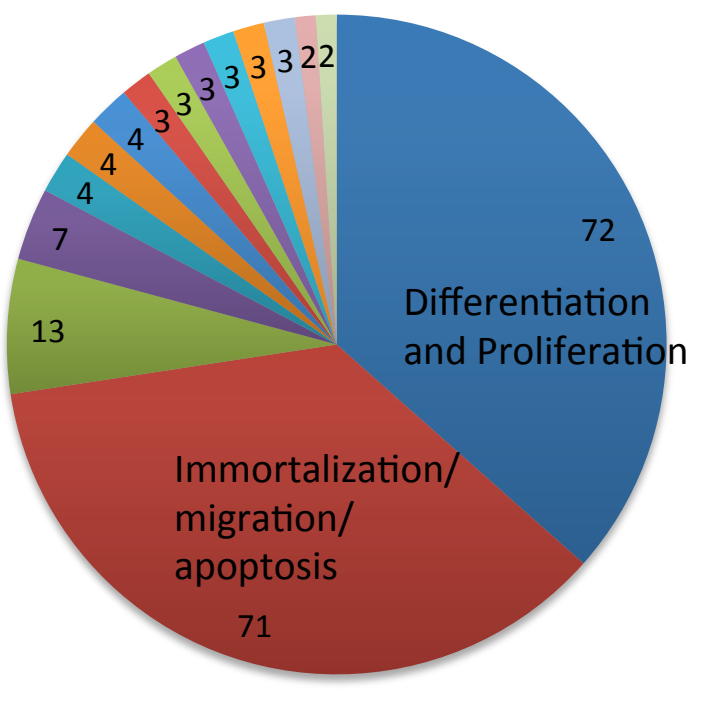
- MYB
- CTDSPL1
- FAM19A2
- gga-mir-155
" gga-mir-155
- CTDSPL2
CHANK2
-NFI1
NFI1 


\section{C7K Tumor}

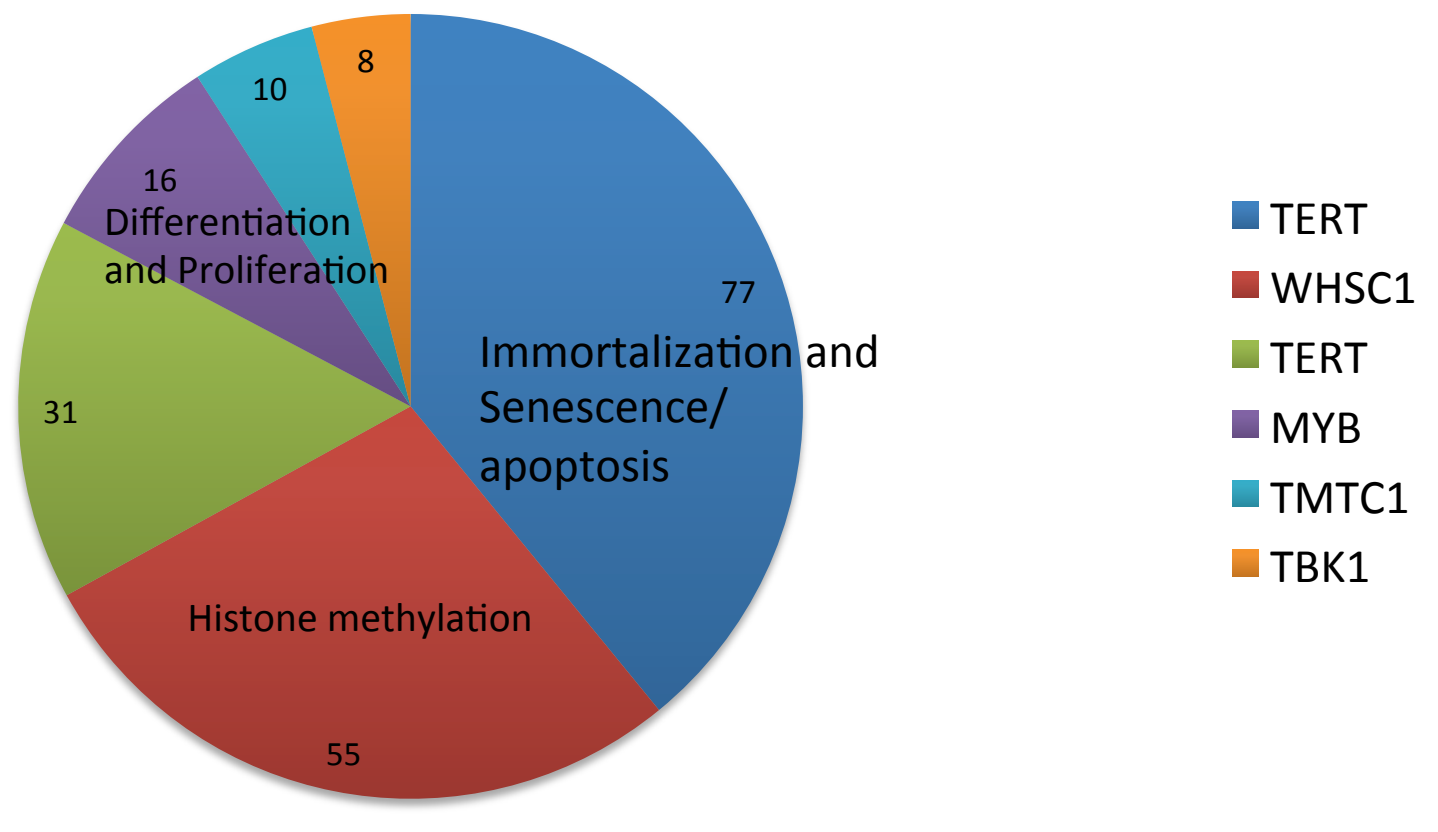




\section{C8K Tumor}

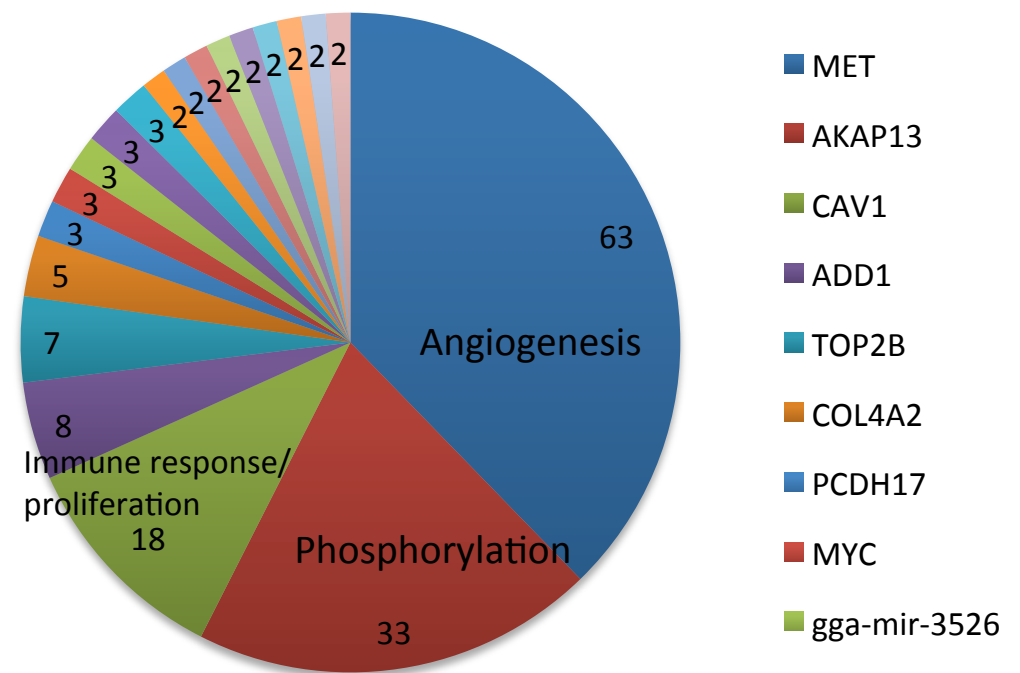




\section{D2K Tumor}

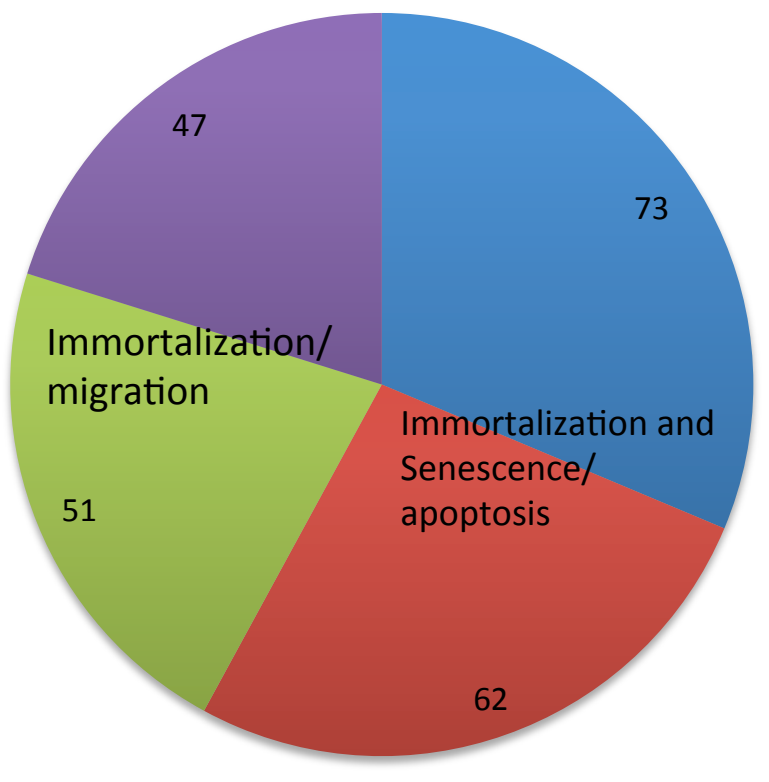

- TERT

- TERT

ฯ CTDSPL1

- CTDSPL2 


\section{D5K Tumor}

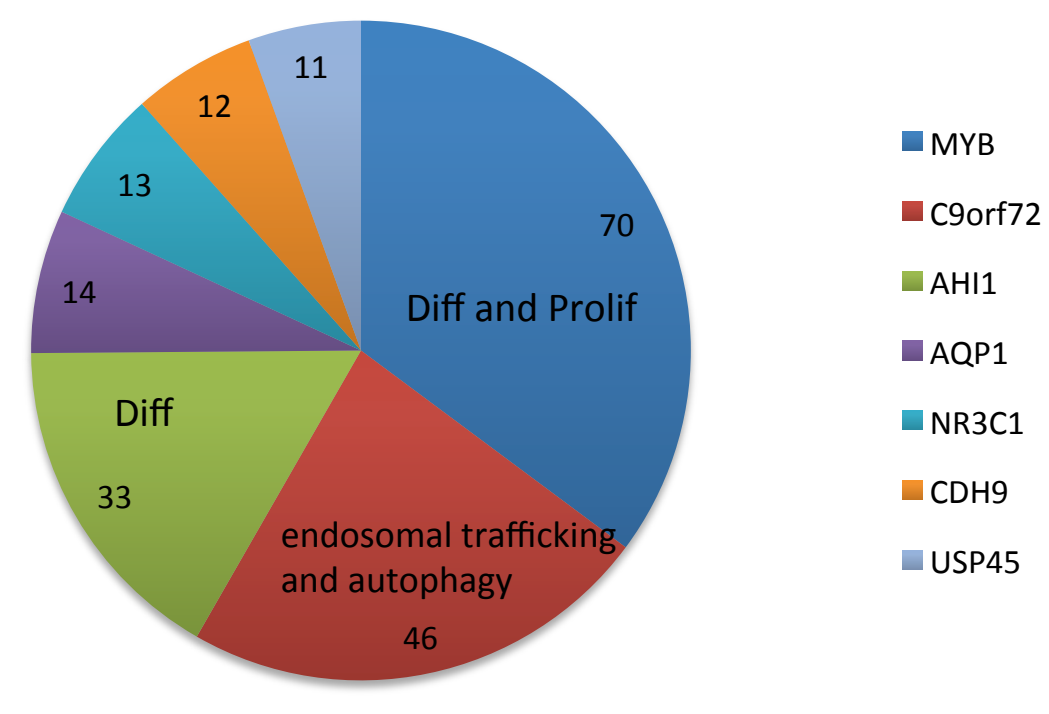




\section{C4K Tumor}

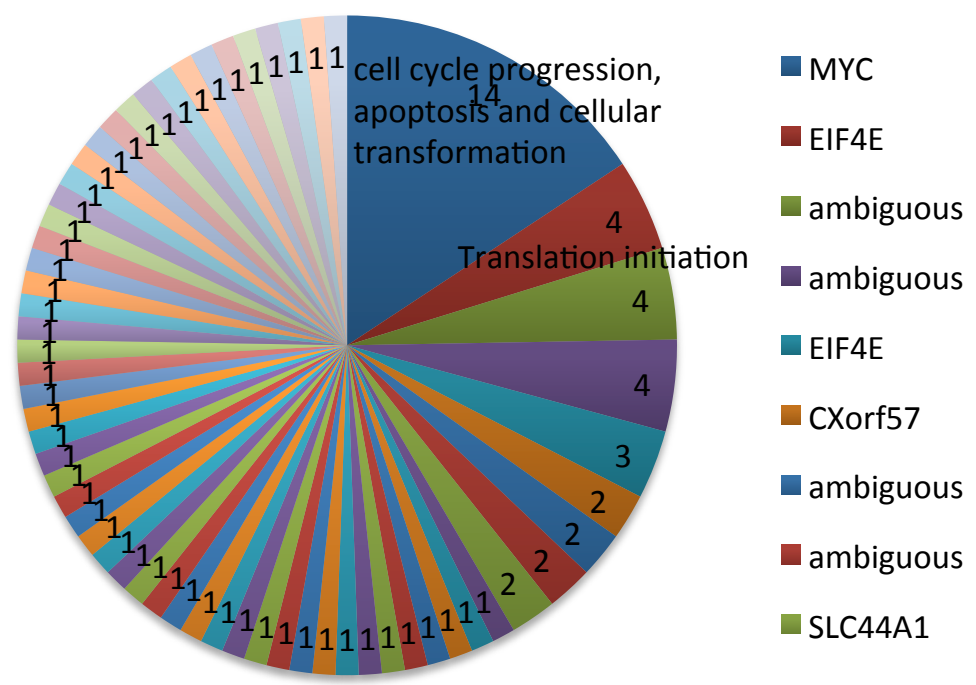

